\title{
3. Film Serials Between 1910 and 1940
}

\begin{abstract}
The third chapter charts the history and development of film serials between the 1910s and the early 1940s. The chapter traces how the operational aesthetic impacted film serial storytelling, as contemporaneous criticism related the serials' portrayed machines and mechanic death contraptions to their 'machinic', that is, continuously propelling narratives. These narratives are presentist, as serials establish their episodes as coterminous with the viewer's own perception of time by reference to previous and upcoming narrative events, and as their narratives expand into multiple spaces as serials connect to newspaper and radio serials and seek to extend their narrative worlds to theater lobbies, local storefronts, and streets. The chapter also delineates the serials' presentational mode of storytelling. Instead of suturing anecdotes into a seamless whole, serials stress the interstices, self-consciously highlighting their montage character and exploring and exhibiting divergent narrative and cinematographic possibilities of the filmic medium.
\end{abstract}

Keywords: presentism, presentationalism, pressbooks, transmedia storytelling, film exhibition, film serials

The operational aesthetic manifests itself visually in specific scenes in individual filmic texts and in corresponding reception experiences: for example, viewers express an interest in process through their reviews or comments, or studios presuppose a similar fascination in their advertising. Such responses surfaced anecdotally — one prominent anecdote appeared, for instance, in the trade-press coverage of a contest issued in relation to one of the most successful early serials. On 13 March 1915, Motion Picture News announced the winner of Thanhouser studio's scriptwriting contest. The studio had promised to award $\$ 10,000$ for the best plot suggestions for their ongoing serial The Million Dollar MYstery. The lucky winner was Ida Damon, a twenty-four-year-old stenographer from St. Louis. The paper

Brasch, I., Film Serials and the American Cinema, 1910-1940: Operational Detection, Amsterdam University Press, 2018.

DOI: 10.5117/9789462986527/CHO3 
describes her as 'a very plucky and self-reliant young lady who has been earning her own living since she was sixteen' (Motion Picture News, 1915b). Another trade journal, The Moving Picture World, reveals somewhat more melodramatically that Damon had been forced to leave school at the age of thirteen due to sickness in the family. She studied at night school and graduated in stenography and shorthand before working as a stenographer. Thus, as the article highlights, 'Ida Damon is a splendid example of the self-reliant and self-educated American girl' (Giebler 1915). Moreover, Mutual's house organ Reel Life ${ }^{1}$ stressed that the 'mayor [...] presented Miss Damon with the certified check, which will make her independent for life' (Reel Life, 1915).

The story of Ida Damon's award-winning success as conveyed in these publications epitomizes many traits that film serials themselves stressed in their female characters. At the time, young, plucky, self-reliant, and educated 'serial queens' crowded American cinema screens (cf. Singer 2001). ${ }^{2}$ Many of them held jobs similar to Damon's: Mary in What Happened to MarY (Edison, 1912), for example, is a clerical worker (Enstad 1995: 74), and Helen, from The Hazards of Helen (Kalem, 1914-17), is a telegraph operator for the railroad (Stamp 2000: 139). Other serial queens, such as Pauline in THE Perils of Pauline (Pathe, 1914), inherit a large amount of money that equally enables their independence-despite their tendency to marry in the end. In fact, Ida Damon appears to be the combined mirror image of the various serial queens that were successful at the time. She is the ideal respondent to answer - and win-Thanhouser's contest.

The contest had more specifically asked viewers of THE MiLLION DollaR Mystery to send in suggestions for the serial's denouement. Ida Damon's submission includes the identification of the heroine's lost father, who then points her to the place where the eponymous million dollars were hidden. The father opens the secret compartment by pushing a button on a picture frame containing his portrait (Motion Picture News, 1915b). By including such a mechanical contraption in her script, Damon resorts to an

$1 \quad$ Although it was Mutual's house organ, Reel Life also covered and advertised films by Mutual's producers Reliance, Keystone, and Thanhouser, according to a note by Eric Hoyt, which accompanies the Reel Life scans on lantern.mediahist.org. Accessed 23 December 2014.

2 Other than by gender, age, and monetary assets, Ida Damon does not resemble the serial queens described by Ben Singer. In Singer's account, protagonists such as Pauline in THE PERILS OF PAULINE are young adults who pursue daring adventures but usually have to be rescued by their devoted future husbands. Singer's study has influenced the film-historical understanding of film serials to an extent that at times obscures the fact that he is identifying the serial-queen melodrama as one genre within film serials at the time rather than describing silent-era film serials as a whole (cf. Singer 2001). 
established formula in film serial scenarios. In fact, machines, technology, and mechanical contraptions were a standard feature of large numbers of serials produced at the time. An advertisement for the film serial ZuDORA, renamed The Twenty Million Dollar Mystery (Thanhouser, 1914/15), for instance, promises 'a revelation of Hindu mysticism and science. It will portray mechanical effects never before seen at the movies.' (Motion Picture News, 1914b). ${ }^{3}$ Ben Singer describes an episode of the serial in which an unknown character hides a wired instrument under a pillow - a dictagraph, as readers learn in the tie-in (2001: 285). Moreover, the final episode of LuCille Love, Girl of Mystery (Universal, 1914) depicts Lucille 'amusing herself as well as the audience, by pressing a series of stops and watching different panels slide back, floors sink down, etc.,', as a review explains (Milne 1914). The Perils of PAuline, while not staging technology as overtly, frequently shows Pauline trapped in machines gone haywire, for example in cars, on planes, or in a hot air balloon (cf. Stamp 2000: 134). One of the most prominent examples, as the following chapter will show, is THE ExPLOITS of ELAINE (Pathe, 1915), which features at least one scientific or technological novelty each episode and based part of its promotion activities on this fact (cf. Stamp 2000: 135; Motion Picture News, 1915a).

The frequency with which serials depicted novel mechanisms and technologies at the time was pervasive enough for Lubin studio to criticize it. An advertisement for The Beloved Adventurer (1914) condemns the incorporation of mechanical attractions and effects: 'Instead of following the not unusual course of writing his stories around some big mechanical effects or twisting machine-made plots to embrace them, the author of "The Beloved Adventurer" has made [...]' (Motography, 1914). The advertisement thus frames The Beloved Adventurer as an alternative to established narrative and attractive formulae. Somewhat inevitably, the advertisement describes that formula at the same time. It underscores that the depiction of technology and mechanisms in film serials was prevalent and that it was recognized as such. Moreover, the condemnation of the serials' 'twisting machine-made plots' reveals an interesting ambiguity: at first glance, the advertisement employs a metaphor of the machine to point to the recurrent showcasing of technology in film serials. However, it also points to the fact that the

3 In order to capitalize on their previous success by creating a sequel, Thanhouser simply renamed Zudora, a serial already in production, The Twenty Million Dollar Mystery. The sequel met limited success and Thanhouser refrained from producing subsequent film serials. Soon afterwards, in 1917, the studio closed its doors entirely. For information on the studio's history, see www.thanhouser.org. 
plots are organized around and according to the machine showcased in the serial, and that the plots themselves work and 'twist' like a machine. When writing the final episode for The Million Dollar Mystery, Ida Damon thus includes aspects that are common in film serials during the decade. Her analysis of the screened installments and of the written texts forming the serial's tie-in allowed her to compose a final episode that corresponded to the narrative paradigms established in the written and filmic texts of THE Million Dollar Mystery. This assessment resonates with the newspaper's description of the stenographer as 'a very keen observer, much given to looking at things from a critical and analytical standpoint' (Motion Picture New, 1915b). Her analytical reading caused her to include a detail that was typical to the serial and to serials more generally, such as the mechanism operating the hidden compartment. Thanhouser did not award the most creative or ingenious plot suggestion but rather the one best matching the formula and style of storytelling that had been established so far. And mechanical contraptions were very much part of that formula and style.

Such an analytic reading of the serial emerges also from William J. Burns' articles on The Million Dollar Mystery. Burns was a renowned detective and scriptwriter at the time. ${ }^{4}$ For the Movie Pictorial, a weekly magazine for film fans, he wrote a series of articles titled 'Helps to the Solution of The Million Dollar Mystery', in which he applied his expertise in deduction to help viewers find the solution to its mystery and win Thanhouser's 10,000-dollar award. Each week's review provided a detailed analysis of an episode as well as guidelines for the viewer's own study of it, which combined into a how-to guide for attentive film viewing. 'Instead of reading the story and watching the films for the sake of entertainment', Burns advises his readers, 'look into every act, analyze every statement'. Attentive followers of the story are thus supposed to

have every fact, in its order, clearly in mind. Then from time to time, you will be aware of the connection between events or conversations in earlier episodes with those in later episodes. Simply being able to recite the events

4 Burns was a Secret Service agent and founder of the William J. Burns International Detective Agency. He published his exploits as 'true' crime stories in detective magazines and appeared in newspaper columns, and he maintained close ties with the film business. From 1921 to 1924, he was the director of the Bureau of Investigation, a forerunner of the FBI ('William J. Burns' 2018). In 1914, an article announcing the release of THE EXPLOITS OF ELAINE (Pathe, 1915) reports that Burns favored the Detective Kennedy short stories, from which the film serial's protagonist detective was adapted, and claims that Burns ordered 100 detectaphones for his offices because they had been described in the stories (The Moving Picture World). 
of the story will not be sufficient. You must ask yourself questions, you must watch causes and effects, and trace effects BACK to causes. (Burns 1914a: 6; capitalization in the original)

What emerges from Burns' advice and encouragement is a reception experience in which viewers pay attention to detail, to minute events and individual utterances, to elements in the background of the image, to details of mise-en-scène, and keep a notebook of their observations. This viewing experience is based on the assumption that the story is a perfect ensemble, a functioning narrative mechanism that only provides viewers with individual parts, with distinct clues that make a whole when viewers 'find the broken bits of evidence and piece them together. But all these stray things must FIT. They must make something perfect — form a pattern that is unmistakable.' (p. 6). Such an understanding considers the story itself a riddle, it equates the serial's narrative with its diegetic mystery. The serial both tells the story of and itself is The Million Dollar Mystery. This faith in a neat organization of the story reframes possible glitches in the narrative continuity of the serial as clues that may help solve the riddle. Accordingly, Burns explains in his second help column that 'we must see what new rays we cast on the dark places. If these further happenings do not fit in perfectly with past events, then the flaw may give us a clue' (1914b:12). Rather than expressing a naïve faith in perfect storytelling, the assumption that individual clues do combine in meaningful ways is the basis for a deductive engagement with the story. The spectator must believe that there is something to discern in order to become a detective - a subject position that will be elaborated further in the following chapter. For now, it is important that Ida Damon's approach and Burns' advice point to two characteristics that, in diverse ways, inform large numbers of film serials in the silent as well as in the sound eras, which this chapter will outline across the decades.

The first characteristic is that storytelling in film serials is always thought to take place in the present, that is, each week's episode points to former and future developments, but during the act of watching the action on screen is always experienced as taking place now. Burns reminds viewers of this fact early in his first article: "The Million Dollar Mystery," keep in mind, is not something that has already happened. IT IS happening right along, from week to week' (1914a: 5). Second, the narratives of film serials are presentational. They engage their viewers in a film viewing experience that takes place outside of the realms of immersion and favors the presentation of narratives over a more realistic representation. Film serials continuously foreground their narrative and cinematic devices, they 
showcase storytelling, and they add visual attractions. Burns notes that the obstacles to detection include not only added information or red herrings but also the lure of action sequences, as he specifically and repeatedly points out. In his first column, he tells his readers that 'what you get is what has been considered necessary to BAFFLE you. Remember that.' (p. 6). The following week's remarks then remind readers that 'the way to discern clues is not to be carried away by action, but to associate that action with whatever relates to it' (1914b: 12). The analytical engagement with the narrative is thus not thwarted by melodramatic attachments alone but particularly by instances of attraction, that is, by filmic moments that also take place at a distance from the viewer. Analytic engagement and the appreciation of visual, narrative, or technological stunts place the viewer in a remote viewing position, in which the story is presented to its viewers rather than exclusively drawing them in.

Burns' description of the deductive approach to film viewing in a sense mirrors the film serials' own combination of convoluted narratives and the showcasing of mechanical contraptions. His Movie Pictorial help column repeatedly explains his deductive approach via a recourse to metaphors of technological advancement and a language of mechanics. He compares the film viewers' failed attempts at discernment to the number of failures Thomas Edison experienced before devising his great inventions; the number of possible clues to be sorted is analogized to a switchboard with one hundred switches; and, in the following week's column, assumption-making is explained by reference to a locomotive that needs an operator to run (Burns 1914a, 1914b). This interrelation of a depiction of technological or mechanical process and prolonged 'twisted' narratives, which surfaces in film serials as well as in Burns' description of The Million Dollar Mystery, is at the heart of the operational aesthetic.

With their presentist and presentational narratives, film serials stress two characteristics that, although they belong to Hollywood film culture more generally, inform film serials in an intensity that results in a rather unique mode of address. In what follows, I will outline these two hallmark attributes from the early days of the serial queens to World-War-II era action serials, thus simultaneously formulating a historical overview of film serials and their place in the institutional environment of early and studio-era film in the United States. I will trace this history twice, first with a focus on the serials' presentist narration and then in a more detailed account of their presentational mode of storytelling. By highlighting the continuities in the serials' mode of address while also acknowledging the striking differences that occur over time, I will show that the unique aesthetic and mode of 
address of film serials is by no means a transitional form of an era before the consolidation of the feature-length film. ${ }^{5}$ Instead, it is particularly the intensity of the presentism and presentationalism of the serials' mode of address that helps to establish serials as an alternative cinematic form and practice across the decades.

\section{Serials are 'Presentist': The Heterogeneous Textuality of Film Serials}

Many aspects of the anecdote of Ida Damon's contribution to THE MiLLION DOLLAR MYSTERY similarly inform the release of the first American film serial. ${ }^{6}$ Edison's WHAT HAPPENED TO MARY, which premiered in July 1912 and attracted approximately two million viewers, also appeared in synchronization with a magazine tie-in, this one in the Ladies' World, ${ }^{7}$ and it focused on a young, female, working protagonist. Its audiences were, like Ida Damon, encouraged to contribute to the creation of the serial by sending in plot suggestions to the magazine. The serial recounts the adventures of country girl Mary in New York City, and the Ladies' World - which, like the serial, appeared once a month-printed novelizations of the chapters alongside film stills that were photographed on the film set (Singer 2001: 213, 276; Enstad 1995: 67, 72). With each publication, the Ladies' World issued a

5 Rudmer Canjels stresses, in accordance with Ben Singer and Shelley Stamp, that despite earlier claims that film serials were a transitional-era form, they were in fact a unique form that was neither short-lived nor featured an ephemeral aesthetic (2011:3).

6 Canjels shows that before the consolidation of the film serial as a form, longer features like those by D.W. Griffith were at times serialized. Singer similarly points to the existence of serialized forms in cinemas before 1912, for instance with the Nick Cater series (Éclair, 1908). Studies such as Canjels', Singer's, and Stamp's differentiate between series with self-enclosed episodes and serials with ongoing narratives and cliffhangers, but they work with a somewhat discursively concurring corpus that includes episodic serials of the early years that catered to the same audience as 'proper' serials, such as WHAT HAPPENED TO MARY and THE HAZARDS OF Helen, but excludes film series of earlier or later periods. What HAPPENED to MARY is thus, despite its episodic structure, the oldest American film serial according to these studies (Canjels 2011: xix-xx, 5; Singer 2001: 210; Stamp 2000: 111).

7 The Ladies' World was a mail-order journal, of which many existed at the turn of the century. They secured their financing through advertisements for mail-order items rather than through subscriptions, and they published serial fiction to secure a steady readership. Enstad stresses that mail-order journals served as a low-cost means to disseminate written fiction to working-class audiences and readerships with limited education (1995: 72-73; cf. Mott 1957: 360, 364-365). Roger Hagedorn's claim that The Ladies' World was a supplement to one of Hearst's newspapers is incorrect (1988: 9). 
contest that awarded 100 dollars for the best proposal for Mary's following exploits. Singer argues that the tie-in primarily served to recruit a film audience from the magazine's substantial readership at a time when film serials needed to maximize their publicity via tie-ins, because their target audience was already saturated with serial fiction in newspapers, magazines, and dime novels (2001: 213, 269; Jess-Cooke 2009: 30). By contrast, Nan Enstad claims that WhAT HAPPENED TO MARY helped the journal, which was almost forced to cease publication because it failed to attract enough subscribers to retain its mailing privileges with the post office, by drawing a large enough readership to allow it to continue (1995: 73). Indeed, although the change in post office policy, which now required magazines to present substantial lists of subscribers and pay for the mailing in advance, had already taken effect in 1907 (Mott 1957:368), circulation data from the N.W. Ayer and Son's American Newspaper Annual and Directory suggests that in 1913, subscriptions to the Ladies' World jumped from an average of between 600,000 and 700,000 to one million (Ayer and Son's 1913: 1153). Edison's serial thus advertised the magazine rather than recruiting film viewers from its readership, which supports Enstad's argument that the cooperation was less a marketing strategy for the film studio than a means of 'rudimentary market research'. This research, she claims, 'served to inform the producers of audience desires but also encouraged readers to actively participate in the fantasy and, importantly, served to constitute and train an audience of fans' (Enstad 1995: 73). Every episode of WHAT HAPPENED TO MARY was thus laid out according to the likes and fantasies of its audience. ${ }^{8}$ The serial evolved alongside its viewers' appreciation and criticism and, by taking viewer response and suggestions into account, it assured viewers that Mary experienced her adventures presently, from month to month, in synchronization with the viewing and reading experiences of her fans.

Tie-ins as both marketing strategies and feedback trackers continued to be pivotal for film serials throughout the serial craze of the mid-1910s. THE

8 This audience was predominantly female at a time when gender hierarchies were being reconfigured, when the suffrage movement was gaining momentum, and laborers in femaledominated industries repeatedly went on strike (Enstad 1995: 69). Serials, according to Nan Enstad, 'contained many political potentials, but in part they offered women fantasies of respectable, serious, and rewarding labor and adventure that countered dominant narratives and ideologies'. Accordingly, serials did not portray factory or domestic workers but clerical workers, telegraph operators, or newspaper reporters (p. 74). Meanwhile, the female protagonists of other serials who were not steadily employed because they had some sort of wealthy inheritance waiting for them nevertheless indulged in interesting adventures outside the confinement of the home. 
Adventures of Kathlyn (Selig Polyscope, 1913/14), which introduced the two-reel form and relied more heavily on cliffhangers or at least on suspenseful episode endings, appeared in synchronization with a tie-in in the Chicago Tribune (Canjels 2011: 16; Singer 2001: 210, 276). ${ }^{9}$ The following year, adventure serials with two-reel episodes, written tie-ins, and contests flooded the market, including for instance Lucille Love, Girl of Mystery, and The PERILS OF PAUline (both 1914), which were released in synchronization with tie-ins in the Chicago Herald and in the newspapers of William Randolph Hearst's syndicate, respectively (Singer 2001: 276). By the year's end, the film industry trades were declaring 1914 'the Year of the Serial' (Vela 2000: 41). The success of Pathe's PAULINE ${ }^{10}$ to some extent hinged on the studio's cooperation with Hearst's newspaper syndicate, which popularized the serial's tie-in with an unusually large number of readers (Dahlquist 2013b: $5-8)$. Studios at the time relied on the trade press to advertise directly to local film exhibitors, who would decide whether to show the serial in their theaters. Such advertisements in trade magazines frequently stressed the wide circulations of their serials' tie-ins (Stamp 2000: 105), encouraging exhibitors to book a particular serial because newspapers already advertised it in their area for them. ${ }^{11}$ The cooperative format proved successful, and 'by the summer of 1914, almost every American film company that could had a serial on the nation's screens', with tie-ins in every major newspaper in the United States and in a range of magazines, reaching 'a potential readership well into the tens of millions' (Singer 1996: 75; 2001: 268-269). ${ }^{12}$

9 The Adventures of Kathlyn consists of thirteen episodes, which were shown weekly. The first episode was a bit longer, which Rudmer Canjels compares to today's television pilots (2011: 16). The serial relates Kathlyn's adventures with wild animals in the Far East, capitalizing on the Selig Polyscope Company's studio zoo (Haenni 2015; Singer 2001: 213; Vela 2000: 40).

10 The PERILs of PAUline is the most frequently analyzed serial today (cf. Stamp 20oo; Singer 2001; Dahlquist 2013a; Denson 2014b; Morris 2014). The prominence of ThE PERILS OF PAULINE is probably related to the fame of Pearl White and to the fact that despite the sole remaining of a nine-episode cut of the serial, it is the earliest serial available in somewhat complete form and it appeared on online platforms before other serials became available on the internet. The original serial consisted of twenty two-reel episodes, probably without cliffhanger endings (Canjels 2011: 17). Although it ranks among the most successful ones, serials such as THE MiLLION DOLlar MYSTERY or THE EXPLOITS OF ElAine were similarly successful.

11 An advertisement in The Motion Picture News highlights the number of newspapers printing the tie-in and the number of people responding to a connected contest. It furthermore insists that 'Any Exhibitor Who Lets This Chance Pass Him Is Not Alive to His Prospects' (Motion Picture News, 1914a).

12 Singer does not take into account more episodic series such as THE BELOVED AdvENTURER, with its novelized version. Therefore, he arrives at the conclusion that 'virtually every' serial had a tie-in. For an extensive list of film serials and the newspapers or syndicates publishing 
Tie-ins served a particular function in establishing a serial's presentist character. Their narratives were perceived as taking place in the present because they were simultaneously appearing elsewhere, thus informing the lives of their fans outside of the film theater in ways that increased and accumulated throughout the history of film serials. Serials were a part of more broadly circulating trans-media texts that 'promoted heterogeneous forms of consumption' (Stamp 2000: 115). Shelley Stamp stresses that

serialized stories released over the course of months and endlessly reiterated myriad formats and products generated an extremely heterogeneous text. While the continuing nature of plot lines guaranteed an ever greater propagation of material, the endless chain of accompanying tie-ins ensured an exponential reproduction of each narrative. As a result, the value fans might accord each incarnation of the tale - whether in print, on film, in song, or captured in a souvenir-diminished in relation to their overall proliferation. (p. 124)

This view of serials as heterogeneous texts corresponds to Rafael Vela's comparative reading of the film serial and its accompanying written tie-in in the case of The Perils of PAUline. The newspaper serial exploited the advantages of its literary form over the cinematic medium in that it described the thoughts and overall inner state of characters, and it included aspects that would have been censored on screen, for example prostitution or drug addiction. Film, in turn, profited from its own medium's abilities when it showed visually exciting instances, for example a hot air balloon ride in the first episode of The Perils of Pauline ('Trial by Fire'). Consequently, both incarnations of the story exploited their respective medium's advantages while working around its disadvantages. The result are two distinct though related stories, which, according to Vela, 'provided complementary, layered versions of the plot' (2000: 68-69). Similarly, Justin Morris affirms the transmedia text's 'multi-textual, multidimensional, and participatory' nature (2014: 45). Although tie-ins probably also helped viewers to understand plot elements (cf. Singer 1993: 497-99; 2001: 279), film serial narratives were heterogeneous and layered, and tie-ins did more than just

the tie-in, see Singer (1993). Moreover, Rafael Vela highlights that tie-ins were only common among producers who released their films through an affiliation with distributors, for example Universal, Mutual, or the General Film Company. Unaffiliated producers would sell their films through local agents who handled the exhibition throughout their region. Serials on this States-Rights market usually did not feature tie-ins until 1920, when National Film's THE SoN OF TARZAN offered a tie-in although it was released without affiliation (Vela 2000: 125-126). 
make up for transitional-era film's supposed lack of a formalized style and cinematography.

The heterogeneity of the multiple incarnations of the stories and their relations to each other also manifested itself in the reception schedules, or lack thereof, according to which the narratives appeared. Although advertisements at times specified the presumably correct order in which fans should consume written and filmic chapters, Stamp's research shows that in some regions the tie-ins were published before the episodes were screened in local theaters, and vice versa in others. This was necessarily the case, as a limited number of film prints circulated between cinemas at the time. This practice resulted in a differentiation of urban center and rural periphery, with the more remote venues receiving the reels at times six weeks after the publication of the tie-in. This was the case with the distribution of THE Exploits of Elaine in the San Francisco Area, where its tie-in ran in the San Francisco Examiner (Stamp 2000:117-118). Additionally, film audiences could migrate between local theaters to catch up on missed episodes or to risk a preview, and local exhibitors invented their own screening schedules, at times showing two or three episodes at a time or screening re-runs of entire serials (pp. 118-119; Canjels 2011: 18). Furthermore, the serializations in local newspapers also differed at times, with individual publications adding stills, portraits, or other visual material or-especially if a town's screening schedule ran behind the serial's original release dates-omitting the contests altogether (Morris 2014: 46). Local viewing and reading practices thus added heterogeneity to the already multi-layered transmedia texts.

The prize contests both fostered the mushrooming of heterogeneous texts and enabled producers, writers, or publishers to control these texts by means of exercising their authority over who would win. Prize contests offered 100 to 25,000 dollars either for correct guesses of upcoming aspects of the story or ideas and suggestions for the plot of following episodes or the overall outcome of the serial (Singer 2001: 265-267; Stamp 2000: 120-122). Viewers of The Perils of PAUline, for example, were encouraged to imagine histories and backstories concerning their serial heroine, which the newspapers then printed alongside the tie-in, again contributing layers to an already multifaceted and convoluted narrative. Paradoxically, the sanctioning of some stories as legitimate assets to the 'PAULINE universe' simultaneously encouraged the production and circulation of an increasing amount of texts written by readers and theater patrons, thus at the same time working against a control over the story's proliferation. Overall, the contests served to organize the viewers' and readers' active engagement with the story, and they 'channel their interest back into the product itself', as Stamp explains 
(2000: 121). Moreover, the contests for PAULINE and other serials encouraged film viewers to read the tie-ins and pay close attention to detail in order to gain the necessary knowledge to write a convincing contest entry. Additionally, they drew returning readerships to the newspapers, because the next issue would list the contest's winners. Viewers and readers continuously engaged in tasks of creative writing and problem-solving that were similar to the detective work and writing endeavors that the serial heroines themselves performed on screen and in the written narratives (p. 122). Pauline, for instance, is a writer of adventure stories in her serial who-in the written tie-in — publishes her stories in the Cosmopolitan (Vela 2000: 106).

Especially serials that featured a contest for each episode, such as WHAT Happened to Mary or The Perils of Pauline, stressed the film serials' presentist focus. Such contests foregrounded narrative development and action in the present rather than a mystery with a deferred outcome. Allowing fans to alter the story as it propels along, serials highlighted the fact that upcoming story elements were not already fixed but would happen in the future. The serials actualized fan response in a narrative feedback loop, which again fostered the experience of the narrative as materializing presently, here and now, as a process rather than as a self-enclosed text. A similar processual and presentist tendency can be observed in the anecdote about Ida Damon: the contest had specifically not been to simply suggest or guess the name of a culprit or the location of the eponymous million dollars of The Million Dollar Mystery. Instead, Thanhouser's contest asked fans of the story to come up with the 'how', to suggest the process leading to the resolution of the plot. ${ }^{13}$ It becomes clear that tie-ins emphasized in multiple ways the presentist nature of the film serial as a narrative form and media product that is continuously on the go. Consequently, they configured film reception and training as a group effort, that is, they encouraged film audiences to identify as a group. Ida Damon not only read the serialized magazine stories and watched the episodes in the theater, she also discussed her film and reading experiences with her mother (Motion Picture News, 1915b). Similarly, Stamp shows that tie-ins, just as the other marketing strategies employed at the time, ${ }^{14}$ encouraged spectators to

13 Paradoxically, Burns' articles treat The Million Dollar Mystery much more as a riddle to be solved than as a task for creative writing. Whereas Damon came up with a solution, Burns' readers aimed to find one to an extent that leads to the suspicion that multiple contests may have been around, or that Thanhouser's contest was itself ambiguous.

14 The publicity for film serials during these years was not limited to tie-ins. Singer lists 'newspapers, magazines, trade journals, billboards, streetcars, sheet music, novelty giveaways, prize contests, coupons, [and] postcards' as means, venues, and options for advertisement, and 
consider themselves part of a group: 'Serials [...] offered multiple sites for consumption, most of which were located outside the space of the theater; and they encouraged viewers to see themselves as part of a community of fans (entering contests, gathering to play games, singing songs together), rather than as isolated "spectators"' (2000: 115). This assessment resonates with the more general history of serial storytelling since the 1880 s in which, as Ruth Mayer explains, 'the entertainment market around penny papers, dime novels, serialized fiction, or the evolving sensationalist yellow press played a seminal role in the production of national and transnational community experiences'. These mass media, moreover, spread 'fantasies of simultaneity, compatibility, and community' (Mayer 2014:16-17). Serials thoroughly embodied all of these aspects.

Tie-ins were part and parcel of a marketing strategy that aimed to maximize profits and to draw returning audiences. However, the coterminous existence of film serials and their tie-ins has implications that exceed the plain observation that they mutually advertised each other. Some of these implications also apply to feature films, which similarly bridged media by adapting previously published stories and novels or by having their stories fleshed out as written texts, for instance in Photoplay or in The Motion Picture Story Magazine, both of which published written accounts of filmic narratives beginning in 1911 (Singer 1993: 492-493; Henderson 2014:13). These publications often added articles about technical aspects of filmmaking 'meant to appeal to the middle-class and hobbyist audiences who were then making Popular Science profitable' (McLean 2003: 3). Even though the 'co-ordinated cross-media synergy' of WHAT HAPPENED TO MARY does mark 'a genuine turning point', as Stuart Henderson stresses (2014: 13), films in general and especially franchises and multifarious forms of 'remaking'15 engaged in conversation with their coexisting texts. Moreover,

he adds that Mary Fuller from WhAT HAPPENED TO MARY even advertised her own original perfume (2001: 265, 213). Among the giveaways and purchasable items were 'calendars, spoons, pillow tops, [and] pin cushions', according to Stamp (2000: 122-123). Such elaborate marketing campaigns were comparatively unique to film serials at the time, as the frequent changes of programming rendered extensive marketing campaigns for individual films almost useless. Film serials, however, recurred each week and thus made substantial advertising worthwhile (Singer 2001: 264-265; Stamp 2000: 107). The emergence of complexly coordinated marketing strategies-especially the widely circulating tie-ins_-co-occurred with the rise of a national market for films. Production companies now formed publicity departments to organize marketing campaigns mostly for film serials and for a few exceptional longer features (Stamp 2000: 108; Canjels 2011: 17).

15 Kathleen Loock introduces remaking as an umbrella term for 'narratives that initially exist as self-contained works of art and are then re-activated, repeated, changed, updated, and 
movie story magazines experienced another peak from the 1930s to the 1950s, often resulting in the simultaneous circulation of multiple written fictions for the same film (McLean 2003: 3-7). What differentiates film serials from these other formats is that, although they weave similar networks of cross-reference, they expanded the engagement with these networks over a predetermined, interrupted length of time. Similar to sequels, serial installments constitute 'a method of renewal and response, particularly in terms of its incorporation of audience response into a continuation of a previously popular production' (Jess-Cooke 2009: 30). Serials translate this renewal into rigid weekly or monthly schedules that continuously reinforce the presence of the narrative alongside and in synchronization with the readers' and viewers' own schedules and timelines. They excess and excel in the constant feedback loops of production and reception that inform serial narratives in general (cf. Kelleter, 2012a: 22), which foster this sense of the narrative as a continuous present.

To this day, the framing of a serialized installment between a 'previously on...' and '...to be continued' reinforces the presentist character of a serial's individual installments during the viewing experience. Somewhat paradoxically, serial episodes - or 'chapters', as they were often called before the advent of television - generate their sense of presence through references to a narrative past and future. The frequent recaps marking the beginning of serial chapters not only serve to recall the relevant information viewers need in order to understand the ongoing action, they also reframe the previous week's present events as now lying in the past. In other words, by reference to a narrative past and by promising a narrative future, serial chapters establish the action between that past and future as 'now'. Therefore, even highly repetitive serials depend on a continuous reactivation of past episodes and thereby emphasize their repetitive character. ${ }^{16}$ The second episode of The Perils of Pauline, for instance, acknowledges the heroine's previous exploits by depicting her taking a rest in response to an increasing journalistic interest in her ('The Goddess of the Far West').

continued', that 'revolve around diegetically consistent plotlines and characters within a joint storytelling universe'. Remaking is thus a practice that includes the production of remakes, sequels, prequels, etc. (2014b: 84 ).

16 Lorenz Engell foregrounds what he calls, with reference to Niklas Luhmann and Elena Esposito, the 'operative memory' of television series. The operative memory is radically presentist and cannot store knowledge. It therefore differentiates repetition and variation in minute decisions rather than based on comparison with past incidents. In other words, repetition is framed as such within a narrative, regardless of whether an instance truly occurred before in the series (Engell 2011: 119). 
Pauline's fatigue thus establishes her adventurousness as continuous and repetitive despite the fact that she only experienced one adventure, that is, in episode one. Throughout the remaining chapters, PAULINE's combination of serial memory and repetitive episode storylines effects a curious imbalance, as all characters seem to remember past episodes except for the serial queen. Episode six thus begins with the acknowledgment that Pauline's (Pearl White) criminal legal guardian Koerner ${ }^{17}$ (Paul Panzer) 'has been seeking methods of eliminating' Pauline, who repeatedly agrees to be placed in dangerous situations, despite her fiancée's (Crane Wilbur) objections ('The Shattered Plane'). Whereas Pauline's obliviousness in these later episodes is a prerequisite for the continuous return of adventures, the serial's reliance on past actions to create a narrative present results in the attribution of the capacity to remember exclusively to male characters. This imbalance surfaces particularly at the end of episode six, when Koerner, in an exclamation that references both a narrative past and future as well as Pauline's lack of memory, assures a co-conspirator: 'we'll get her next time' ('The Shattered Plane'). A similar conflation of a narrative future orientation and an acknowledgement of repetitive episode plots occurs in PEARL OF THE ARMY (Pathe, 1916), when a representative of the preparedness serial's sinister Foreign Council remarks with respect to an attempt to thwart Pearl Travers' (Pearl White) investigations: 'get to work on it at once, ... there must be no slip-up this time' (episode 5, 'Somewhere in Grenada'). Such a self-description of serials as presentist narratives also provides a new angle to the notion of training. Film serials and their tie-ins familiarize their viewers with a repetitive formula, in which new episodes offer repeated variations of the same plot rather than a true forward momentum and narrative evolution. As Ida Damon's example illustrates, prize contests provided an opportunity for audiences to apply their acquired skills. The fact that all these efforts focus on the present, that is, that they refuse to pass beyond the moment of becoming, in a sense frees the idea of training from its need to be applied practically, outside of the narrative environment from which it originated. Although the skills will be put to the task elsewhere, as they help organize or 'manage' the contingency of options that characterizes the mass-cultural environment of modernity (cf. Brasch \& Mayer 2016; Mayer 2016), they are not acquired with such an intention in mind.

To an extent, cliffhanger endings dissolve the paradoxical relationship of memory and repetition in serials because they reformulate the promise

17 In the edited nine-chapter version of the serial, the villain who in the tie-in appeared as Raymond Owen is renamed Koerner, maybe with reference to Paul Panzer's German nationality. 
of a narrative 'again' in terms of continuation-despite the still repetitive plot structures. The cliffhanger structure increasingly became a norm of cinematic serial storytelling, and it co-occurred with the introduction of story recapitulations at the beginning of individual episodes. Cliffhangers and story recaps, in turn, have their own implications for the serial memory, which become apparent when considered in the light of the notion of meaning making in Niklas Luhmann's systems theory. According to Luhmann, the individual moment in time exists only with reference to past and present occurrences (Krämer 1998: 570; Luhmann 1997: 20-24). The notion of meaning gains particular relevance for film serials in its relation to the contingency of possible events in the world - in this case, in the narrative world of a particular film serial. Luhmann clarifies that references to the past point only to the contingent operations, the results of which can be apperceived in the present. References to the future, by contrast, suggest an endless array of possibly upcoming observations (1997: 21; see also Engell 2011: 117-118). ${ }^{18}$ The plot recaps provided in individual episodes radically reduce past plots to the minimum of information necessary to understand the action of the respective episode. In other words, the chapter introductions do not fill in possibly uninformed viewers about the narrative, but they offer a shortcut entryway into the present episode. By referencing a reduced narrative past and by pointing to the contingent narrative future, serials not only establish each episode as taking place in the present, they also make meaning in the first place.

In addition to constructing presence by turning to a narrative past and future, title cards of film serials often employed a grammatical present tense that constructed particular narrative information as being simply there instead of resulting from anything in particular. A diegetic newspaper article in the second episode of THE PERILS OF PAULINE, for instance, established her as 'that present day heroine so much talked about' ('The Goddess of the Far West'), and a newspaper article in episode six informed her that 'much activity is taking place at the airdrome' ('The Shattered Plane'). Similarly, PeArL of THE ARMY's eponymous serial queen is granted the episode's first spoken sentence when she informs her father in episode four, 'I tell you, father, I'm on the trail of the Secret Menace!'-informing the audience just as much as the diegetic father figure (episode 4, 'War Clouds'). Moreover, the pilot episode of

18 The original quote, in German, reads: 'Soweit Rekursionen auf Vergangenes verweisen (auf bewährten, bekannten Sinn), verweisen sie nur auf kontingente Operationen, deren Resultate gegenwärtig verfügbar sind, aber nicht auf fundierende Ursprünge. Soweit Rekursionen auf Künftiges verweisen, verweisen sie auf endlos viele Beobachtungsmöglichkeiten, also auf die Welt als virtuelle Realität, von der man noch gar nicht wissen kann, ob sie jemals über Beobachtungsoperationen in Systeme (und in welche?) eingespeist werden wird' (Luhmann 1997: 21). 
The Exploits of Elaine establishes that 'the secret society "The Clutching Hand" continues its sinister exploits' and Elaine's (Pearl White) father already takes an unexplained interest in uncovering the identity of the secret society's eponymous leader. Such notions reinforce a narrative presence on the film screen that also finds its equivalent off screen, in a context of marketing and paratextual endeavors that weave a referential network outside of the cinematic institutions. The following pages will pinpoint the practices by means of which serials established their presence extra-cinematically in the lives of their fans across the decades. The analysis then returns to the serials themselves in an exemplification of their presentist mode of storytelling in the sound era.

\section{Presentist Storytelling in the 1920 and $1930 \mathrm{~s}$}

A rough timeline of the history of silent serials in the 1920s would show three phases that followed the initial serial craze. The first of these phases lasted from about 1917 or 1918 to 1923 . These years in the motion picture industry were characterized by unstable relations between distributors and exhibitors, as the industry lacked a uniform standard of distribution and local exhibitors frequently engaged in disputes over distribution contracts (Maltby 2013: 143-144). Additionally, serials lost their national tie-ins in newspapers and magazines. Previously, newspapers had paid for the rights to print a particular tie-in or at least published them free of charge, resulting in the fact that 'virtually every American serial before 1917 was packaged with a tie-in that ran its duration' (Singer 2001: 276). Towards the end of the 1910s, however, publishers increasingly thought of them as advertisements and thus charged film producers and distributors accordingly. Moreover, both producers and exhibitors began to consider it unwise to give away or 'spoil' the story before the screening (Singer 1993: 495; 2001: 278). During these years, film serials were increasingly targets of censorship. From the mid-1910s onwards, censors across the United States demanded that violent scenes be edited out, and they often practically dissected entire episodes (Vela 2000: 154-155). ${ }^{19}$ In 1919, the National Board of Review ceased to approve film serials in general, causing

19 In 1920, Arthur B. Reeve (author of, among others, The Exploits of Elaine and The Mystery MIND, and vice-president of Supreme Pictures) spoke out against a proposed Oklahoma bill to prohibit the interstate transportation of 'thrills', arguing that 'if the reformers, cranks and censors have their way the law will eliminate from our plays, literature and cinema stories all the vital human emotions. We shall have a "perfectly lovely soda pop party" where inane ingenues will display the latest thing in chiffons and pretty faced boys will advertise somebody's "correct college clothes"' (Reeve 1920). 
a public relations disaster for their producers just as wealthier competing studios were moving towards vertical integration (pp. 208-209). As a result, in the fall of 1921 and throughout 1922, Universal exclusively produced censor-proof serials. Similarly, Pathe produced serials that, while retaining thrills, worked without violence and gunplay, thus gaining the approval of the National Parent Teacher's Organization and eventually of the Censor Board (pp. 210-211). ${ }^{20}$ However, Rafael Vela notes that at least in one rural Illinois theater in 1918, serial audiences were less than 30 percent juvenile (p. 140). Audiences do not seem to have been very different in 1922, when the implemented changes drove away the adult audience - a group large enough for Universal to quickly adapt and repeal their censor-proof style. The studio only released two more wholesome serials in $1923,{ }^{21}$ and serials remained, as Vela stresses, 'dependent on a mixed audience' (pp. 212-213).

Whereas serial queens Pearl White and Ruth Roland continued to capitalize on their stardom during this phase, studios also sought to make up for the lack of tie-ins by referencing other public discourses through the showcasing of non-cinematic celebrities. Thus, Rolfe's THE MASTER Mystery (1919) featured the illusionist and escape artist Harry Houdini, and The Mystery Mind (Supreme Pictures, 1920) showcased the French hypnotist J. Robert Pauline (Exhibitor's Herald, 1920b). DAREDEVIL JACK (Pathe, 1920) starred heavyweight boxer Jack Dempsey, and the light-weight boxing champion Benny Leonard appeared in THE EvIL EYE (Hallmark, 1920) (Exhibitor's Herald, 1920a). Pursuing a somewhat different strategy, the plot of The Hope Diamond Mystery (Kosmik, 1921) capitalized on the public discourse about the mysterious Hope diamond and its previous owner, the former noblewoman-by-marriage May Yohe. On the one hand, celebrity characters were apparent advertising stunts (cf. Vela 2000:133). ${ }^{22}$ On the other hand, even though this kind of star discourse did not as readily feed into a transmedia narrative, the showcasing of stars provided another means for serials to transcend the boundaries of the narrative and carrier medium and

20 Universal produced The Winners of the West (1921), Adventures of Robinson Crusoe (1922), With Stanley in Africa (1922), and In the Days of Buffalo Bill (1922). Among Pathe's censor-proof serials were HuRRICANe Hutch (1922) and The White EAgLE (1922) (Vela 200o: 210-211). 21 In the Days of Daniel Boone and Oregon Trail (both Universal, 1923). Two years later, in 1925, W. Ray Johnston, President of Rayart Pictures, similarly insisted that serials needed to cater to mixed audiences, therefore Rayart's BATTLING BREWSTER includes a noted cast (including Helen Holmes), 'good action', and is 'photographed on a par with the big features', but it also features a skillfully riding juvenile actor to please the child audience (Exhibitor's Trade Review, 1925a).

22 The pressbook for DAREDEVIL JACK, for instance, stresses the exhibitor's opportunity to profit from the immense press coverage of its celebrity protagonist. 
to integrate synchronously into the fans' weekly routines through magazine and newspaper portrayals. Stars or public figures more generally helped establish the connections to the outside world upon which serials rely.

Another means of producing serials that tapped into existing discourses was to arrange tie-ins with, or to produce adaptations of, already popular novels or newspaper serials. In 1917, Paramount's Who Is Number OnE? appeared alongside a corresponding novel, and the film serial was advertised in bookstores. Similarly, in 1919, Pathe released The Black SECrET, an adaptation of Robert Chambers' already running print serial In Secret. The serial novel later appeared as a bound volume, enabling a marketing strategy that included advertisements for the film serial in the Doran Publishing chain of bookstores (Vela 2000: 131-132). Such co-operations worked on a local basis: the previous cross-regionally syndicated tie-ins, which were organized to a large extent by the studios, were now replaced by marketing suggestions in pressbooks and trade magazines, and the organization and actualization of these ideas was passed on to local theater owners or managers. An early example of this is The Adventures of TArzan (Weiss Brothers/Numa Pictures, 1921) and its exploitation stunts. The Exhibitor's Trade Review noted that the film studio's publicity director had 'devised numerous novel and practical stunts that should aid the exhibitor in keeping his box-office staff working at high speed. What is more, the suggestions are not only practical, but can be utilized without the expenditure of any huge amount of money. They are inexpensive and attractive' (Exhibitor's Trade Review, 1921). Exhibitors were advised to co-operate with local bookstores selling the Tarzan books, who could furnish their windows with cutouts from the film posters to create a miniature jungle. Similar co-operations were suggested with toy stores, music stores (there were Tarzan songs as well), bird stores, and fur shops, and movie theaters were encouraged to use wild animal 'perambulators' for the day of the show and, if possible, to borrow a caged lion from a local zoo. Furthermore, the article urged exhibitors to 'follow the press book suggestions for newspaper display advertising as closely as you can', for instance by convincing local editors to publish the reviews and feature stories that the pressbook offered, especially as 'Monday is usually a slow news day for the papers and they will welcome features that carry interest' (Exhibitor's Trade Review, 1921). ${ }^{23}$ A particular

23 Note that advice for the exploitation of feature films in the 1920 s at times also asked local stores 'to create window displays linking their goods, whether they be pipes, sheet music, or drugs, to a film at the local cinema' (Horak 1989: 29). However, advertisements for feature films would have been of shorter duration. 
serial and its advertisement thus aimed to take over a small town center to an extent, which meant that the serial would quite literally surround its audiences. Whereas some of the marketing suggestions seem outrageous and/or impossible, similar suggestions fill the pressbooks for film serials at the time. This practice of passing on the responsibility for the proper 'exploitation' of a serial to the exhibitor became common for every serial in the sound era, as well as for numerous features. Moreover, the suggestions for co-operation with local stores epitomize the role that local theaters played in their communities, where they prevented business activity in general from moving to the larger cities: 'Like the grocery, clothing, and drugstores in Main Street's retail zone, small-town movie theaters were economically inconsequential individually, but taken together, they were critical to their community's commercial activity' (Maltby 2013: 140-141).

The second phase of 1920 s film serial production begins around 1923. Insecurities in the film business led to the establishment of the trade association, the Motion Picture Producers and Distributors of America, in 1922. The MPPDA devised a Standard Exhibition Contract, ${ }^{24}$ which governed the distribution of films to independent cinemas and strengthened the distributors' rule for more than a decade to come, stabilizing the business and minimizing the cutting of films by local exhibitors (Maltby 2013: 143-144). By now, many of the big studios were vertically integrated, that is, they merged into business conglomerates increasingly controlling the production, distribution, and exhibition of their films (Sklar 1994: 141). Companies such as Famous Players-Lasky (including Paramount), Fox, and Metro-Goldwyn-Mayer dominated the market, keeping the studio system firmly in place. ${ }^{25}$ They operated their own theater chains, which concentrated on lavish houses in metropolitan centers, thereby ensuring that the coverage of the equally urban-centered press focused on their films. These developments concluded the permanent obliteration of large synchronized tie-ins, as national newspaper syndicates based

24 According to Maltby, 'the SEC, the instrument by which the major distributors did business with the fifteen thousand independent exhibitors across the United States, was the most ubiquitous document of the Classical Hollywood cinema: approximately 750,00o of these contracts, governing eleven million film movements, were signed every year'. The contract was used until 1935 (Maltby 2013: 142).

25 The first studios uniting production, distribution, and exhibition were Paramount in 1919 and Loew's-Metro in 1921. By the late 1920s, the market would be divided between Warner Brothers, Paramount, Metro-Goldwyn-Mayer, Fox Film Corporation, and RKO. Universal, Columbia, and United Artists were in production and distribution, but released their films in cinemas of the other studios. This system ended in 1948 with the Paramount Consent Decree, which forced companies to separate production and exhibition to avoid monopolies (Horak 1989: 6-7, 11-12). 
their flagship publications in urban centers, where serials were ceasing to be shown. Moreover, a large-scale dissemination of the newspaper tie-ins relied on the comparatively simultaneous appearance of serial episodes across the nation, but serials were now booked and screened by local exhibitors and small independent chains according to their own schedules.

The situation further intensified as the consolidated corporations imposed block-booking on local theaters, forcing exhibitors who wanted to show a particular feature to rent a plentitude of films alongside it - often enough to effectively fill an independent house's screening schedule. This booking system practically closed the market off for independent producers (Horak 1989: 24). The exclusively non-integrated producers of film serials now had to draw most of their profits from small independent theaters and therefore cut production budgets (Vela 2000: 162). However, to maximize the profits they could garner from these neighborhood houses and to prevent audience dissatisfaction, the biggest producers of serials, Pathe and Universal, started to produce more serials ${ }^{26}$ but with less episodes each, reducing the typically fifteen to eighteen episodes per serial to ten or twelve episodes by the mid-1920s (p. 210). As a result, serials rebounded to a certain extent, and in 1926 Pathe confidently announced that their chapter plays ran in some forty percent of American cinemas (p. 221). Thus, whereas histories of the studio system provide an understanding of monopolization that makes the possibility of serials-and independent film production in general-difficult to grasp, the continued production of serials itself bears witness to their profitability. In a way, the numbers speak for themselves.

On 14 February 1925, the Exhibitor's Trade Review focused on film serials in a special issue that grants us a closer look at the form at this point in the history of the film business. The issue's editorial admits that after the initial heyday of the form in the 1910s, serials had 'been run into the ground by men who had no appreciation whatever of their possible merit or value' and who produced serials that were 'badly done'. New serials, the editorial postulates, were unquestionably better and paved the way for 'a revival of the serial product at a time when it is solely needed to meet a serious selling problem that involves the entire industry' (Exhibitor's Trade Review, 1925b). Another editorial piece in the same issue argues that although serials were of less quality than premium features, they would benefit the theaters suffering 
from two or three slow nights a week, especially as the influx of radio sets in homes kept patrons away from the movie theaters (Exhibitor's Trade Review, 1925d). ${ }^{27}$ The editorial elaborates on this point, claiming that the impact of radio and the lack of continuity in cinematic products caused the instability of picture attendance from which theaters suffered at the time. Film serials promised such continuity but theaters had nevertheless discontinued showing them because viewers had complained about the serialized form. Comparing the film serial to serial magazine fiction, the editorial explains a paradox of seriality: the audiences or readers who complain about the fact that a story is presented in installments are often the same ones who reliably follow the story until its end. 'Showmen, good showmen, have cut out the serials on the ground that motion picture fans object to them. Of course they do. Just as fiction readers generally object to them. But this happens to be one of the rare cases where it is good business to give the public something it says it doesn't want' (Exhibitor's Trade Review, 1925c).

In the same issue of the Exhibitor's Trade Review, Elmer Pearson, Vice President and General Manager at Pathe Exchange, explained that the studio had 'formulat[ed] an entirely new serial policy' beginning with its 1924 releases because previous serials had been so repetitive that 'the audience was able to outguess the author, nine times out of ten'. Pathe's new serials were based on classic stories, such as James Fenimore Cooper's 'Leatherstocking Tales', or on stories by popular contemporaneous authors such as Mary Hastings Bradley or Albert Payson Terhune. Pathe also began re-editing serials into features (Pearson 1925). Nevertheless, the studio continued to rely on the successful marketing stunts tried a few years earlier. Thus, another heavyweight boxer, Gene Tunney, starred in Pathe's THE FIGHTING MARINE in 1926. Other studios similarly starred widely known persons or comparably famous fictional characters. OfFICER 444 (Goodwill, 1926), for instance, starred police chief and publicly acclaimed criminologist August Vollmer. ${ }^{28}$ Universal took a similar approach when they revived the scientific detective Craig Kennedy, who had solved cases for instance in THE Exploits of Elaine in 1915, in The Radio Detective in 1926. The story by Arthur B. Reeve had been serialized in Boys' Life, the monthly magazine of the Boy Scouts of America, in 1923 and 1924 (Reeve 1923). With the release

27 The writer for the Exhibitor's Trade Review thus makes an argument similar to Roger Hagedorn's more general theoretical observation that seriality is a medium's means to sustain interest when rivaled by another medium. Nevertheless, the earlier proliferation of tie-ins also complicates Hagedorn's claims (cf. Hagedorn).

28 For further information about August Vollmer, see Cole (2001) and chapter five of this volume. 
of the serial, the magazine published a report on the film's production, which was illustrated with stills. Serials such as The RAdio Detective or OfFICER 444 exploited an already existing media discourse economically, but they also created narratives that point beyond their diegetic confines on screen. The case of The RAdio DetECTIVE additionally illustrates how some producers sought to limit their reliance on local cinemas more generally. In January 1927, Universal published an ad in Boys' Life thanking the Boy Scouts of America for their official endorsement and telling the children to have their scout master write to Carl Laemmle to ask how the screening could be arranged if the serial was not shown in their vicinity (Boys' Life). ${ }^{29}$ Whereas Universal thus aimed to recruit viewers from the boy scouts, its marketing strategy acknowledged the possibility of either the lack of local cinemas or an exhibitor's inability or unwillingness to show the serial. Universal thereby continued a strategy commenced five years earlier when it had begun to sell its films to non-theatrical outlets, as portable projectors enabled film screenings for example in churches and YMCAs-a strategy that was much debated, as such arrangements drew viewers away particularly from local, exhibitor-owned theaters (Vela 2000: 158-162). As this example illustrates, film serials in the 1920 continuously strove to find new cross-media promotions as well as venues for their screenings, because the advancement of the studio system threatened not only independent producers but the serial as a cinematic form more generally. As a result, film serials continued to be interwoven into networks of multiple institutions, businesses, and media, and their reach exceeded the confines of the film theater. Such developments again underline the serial's presentism in both a temporal and a spatial sense.

The final phase in silent serials began in 1928 or 1929, when the small theaters that bought serials had to face the challenges of the transition to sound, the Great Depression, and ensuing changes in the film business that led to the termination of many independent studios. Pathe, the biggest producer of film serials since 1914, joined the larger, vertically integrated company RKO and terminated film serial production in 1929. The rural, subsequent-run cinemas that constituted the main outlet for film serials were lagging behind in the rewiring for sound films, so that film serials would have had to be produced in both silent and sound versions-a

29 The ad also asked children to send in ten cents to get an autographed picture of the serial's star Jack Dougherty, and it announced Universal's following serial called Fighting WiTH BUfFALO BILL, the name for which Mr. R. Jacobs from Brooklyn, NY, received $\$ 250$ in a contest (Boys'Life). 
financial burden that the small profit margins of the States Rights market could not (or would not) shoulder. The bulk of film serial production thus remained with Universal and a new upstart on the independent market: Mascot Pictures (Vela 2000: 224-226). $\cdot^{30}$

Whereas Hollywood's transition to sound generally dates to 1926 and 1927- somewhere around the release of Max Murnau's SUnRISE (Fox, 1927) and Alan Crosland's The Jazz Singer (Warner Bros., 1927) — film serials with synchronized sound did not appear until two years later. Although exact pioneers are difficult to determine, among the first sound serials were King OF The Kongo (Mascot, 1929), The Voice From the Sky (Ben Wilson Productions, 1930), and The Indians ARe Coming (Universal, 1930). ${ }^{31}$ The end of the silent era and the beginning of film sound was commemorated with nostalgia for the early years of the serial craze. One of the final silent serials, The Chinatown Mystery (Syndicate, 1928) bears evidence of an awareness that an era in filmmaking was coming to an end. Produced when the introduction of sound was well underway, the serial features 'the mysterious 13', a group made up entirely of former serial villains and heroines, male and female. These are introduced in sequence, revealing new members every couple of episodes, although missing footage or a producer's quirk results in the naming of only eight cameos: Francis Ford, Paul Panzer, Rosemary Thebe, Sheldon Lewis, Grace Cunard, Harry Meyers, Helen Gibson, and George Chesbro. ${ }^{32}$

30 The Indians Are Coming (Universal, 1930), for instance, was produced both as a silent and as a sound serial.

31 King OF The Kongo was a part-talkie, but most of the original sound discs are missing. Some scenes remain, however, and the first sound sequence seems to appear in episode five. THE VoICE FROM THE SKY, by contrast, is a lost film, but some of its sound remains. Individual episodes of THE INDIANS ARE COMING have been archived, for instance at the Film and Television Archive at the University of California in Los Angeles. Authors name different serials as the first sound serial: Roy Kinnard claims it was THE INDIANS ARE COMING (2012: 22), for instance, and Cynthia Miller believes it to have been ACE OF SCOTLAND YARD (Universal, 1929) (2009: 63).

32 Francis Ford was an actor, writer, and director who directed about 170 films and acted in about 500 (Usai). He directed LuCILle Love, Girl of Mystery (Universal, 1914) and The Mystery OF 13 (Burston, 1919), both of which he also acted in, and he wrote and directed OFFICER 444 (Davis, 1926). Paul Panzer's most notable role was as the villain Owen/Koerner in The PerILS of PAuline (Pathe, 1914). Rosemary Thebe played lead roles alongside Francis Ford in ThE Silent Mystery (Burston, 1918) and The Mystery of 13. Sheldon Lewis was known for acting as 'the Clutching Hand' in The Exploits of Elaine (Pathe, 1915) and as the title villain in The Iron Claw (Pathe, 1916), Grace Cunard was lead actress in LuCille Love, Girl of Mystery (alongside Ford). Harry Meyers cannot be placed. Helen Gibson is best known for THE HAzARDS of Helen, 1915-1917. George Chesbro appeared in Hands Up! (Pathe, 1918) and in The Hope DiAMOND MYSTERY (Kosmik, 1921). 
A similar sense of nostalgia carried over into the early sound era, when producers capitalized on what Kathleen Loock has identified as a trend in Hollywood features at the time: the production of 'talker remakes', that is, the remaking of silent films in the sound era (Loock 2016). In 1933, Universal released The Perils of PAuline, and detective Craig Kennedy and the master villain from The Exploits of Elaine (Pathe, 1915) reappeared in The Amazing Exploits of the Clutching Hand (Weiss Bros., 1936) three years later. Although these serials tell new stories, ${ }^{33}$ newspaper articles in the corresponding pressbooks relate them to the history of their silent predecessors. The pressbook for THE PERILs of PAULINE, for instance, calls the serial a 're-creation', which would educate more recent serial fans about the history of the form:

For six months Universal made intensive preparation for a great serial adventure. Carl Laemmle, Jr. realized that to re-create the world's most famous serial, "The Perils of Pauline," would be a great money-maker for exhibitors. The new generation of theatre-goers has never seen this tremendous war horse of a score of years ago. But there isn't a mother's son or daughter in the United States who doesn't know the name, "Perils of Pauline."

The term 're-creation' itself suggests an ambivalence of nostalgia and 'making present'. On the one hand, The Perils of PAuline conjures up the history of the form, pointing out its historical relevance as a means to assert its contemporaneous one. On the other hand, the existence of a new THE PERILS of PAULINE (instead of, for example, a possible re-release of the silent serial) effects a reliving of the history of film serials, starting in the sound era just where it started in the silent era. In a sense, the serial references film history and offers an ersatz history at the same time. The 're-creation' of THE PERILS OF PAUline thus relocates the serial to the present, complete with its twodecade history. A similar treatment of film history informs THE CLUTCHING HAND, which restages Detective Kennedy's quest to reveal the identity of the Clutching Hand as it was first visualized in The Exploits of Elaine (Pathe, 1915) but uncovers a different fictional character beneath the crook's disguise. Correspondingly, the serial's pressbook assumes the audience's familiarity with the actress Pearl White, but not with the 1915 narrative. The marketing

33 The Amazing Exploits of the Clutching Hand was in fact based on Arthur B. Reeve's final novel of the same name. THE PERILS OF PAULINE recasts the protagonist as the daughter of a chemist and archaeologist and has Pauline travel to Asia in pursuit of a secret formula. 
thus equips THe CLUTCHING HAND with historical relevance, but its story is firmly placed in the 1930 s United States, with no narrative past referenced. ${ }^{34}$

Film serials thus transitioned into the sound era by reasserting their 'crossgenerational appeal' (Barefoot 2011:181). Whereas juvenile viewers at Saturday matinees are often considered their core audience, the most acclaimed serials were typically those attracting an adult audience as well. In many theaters, serials were reliably part of the Friday night program, and they frequently appear on the bills of other weeknights as well (Higgins 2016: 9-12; Barefoot 2011: 176-178). Children also frequented those evening showings, but they did not constitute the majority of the viewers. As Guy Barefoot summarizes,

the film serial's survival into the 1930 s and beyond was not restricted to Saturday children's matinees. Serials were made with children in mind and attracted a sizeable child audience, but that audience was not limited to children, nor were serials only made with children in mind or watched only by children. (p. 183)

Numerous pressbooks released at the time suggest ways for local exhibitors to work the 'adult angle' of a serial, often with different suggestions for male and female viewers. ${ }^{35}$ Moreover, sound-era serials frequently adapted stories that were already broadcast on radio, whose audience around 1940 was two-thirds adult (p. 180).

Although a small group of film studios continued to control sound-era domestic film distribution, film serials reached an increasing audience. At least 233 sound serials were produced in the United States, and they were shown in almost half of the county's cinemas, predominantly in rural areas (p. 168, 175). $3^{6}$ The biggest studios-Mascot/Republic, Universal, and Columbia — released about four serials annually, providing one episode a week for an entire year (Higgins 2016: 5). As Barefoot ascertains, 'in the second half of the 1930s it was seen as a developing rather than declining form

34 The pressbook for The Clutching Hand recounts that 'in 1914, Reeve introduced his method of detection to the movies in one of Pearl White's most famous serials, "The Exploits of Elaine". This stirring chapter-play still holds the world-record both for the number of episodes included in it and the receipts from the gross sales all over the universe'.

35 Examples include Mandrake the Magician (Columbia, 1939), Holt of the Secret Service (Columbia, 1941), and CAPTAIN AMERICA (Republic, 1944). Universal placed less emphasis on adult viewers, it appears.

36 Occasionally, sound serials showed at Broadway theaters. According to Barefoot, the Los Angeles Times noted on 27 March that 'Carl Laemmle takes pride in pointing out that Universal serials are shown at the Roxy'. Moreover, in 1938 THE LONE RANGER was shown at the 1700-seat Criterion Cinema on Broadway in New York (Barefoot 2011: 175, 181). 
of cinema' and the serial 'did constitute an important part of what audiences watched' (2011: 184). In fact, serials experienced a second heyday in the 'golden age' of sound serials between 1936 and 1946 (Higgins 2016: 8, 98). During these years, serials were not only numerous but also particularly presentist, both in their styles of storytelling and in their marketing approaches.

Golden-era serials particularly drew on the success of comic strips at the time. A fan of 'the funnies' reading the New York Journal and American ${ }^{37}$ in the fall of 1937 could have found Flash Gordon and Ace Drummond in the Sunday supplement on 3 October, both of which were adapted by Universal in 1936 (New York Journal and American, 1937a). The following Monday, the same newspaper would carry Secret Agent X-9, Radio Patrol, and Tim Tyler's Luck - all of which were Universal serials in 1937 (New YorkJournal and American, 1937b). Moreover, the same issue featured Mandrake the Magician, which would become a Columbia serial in 1939, and King of the Royal Mounted, which was turned into a film serial by Republic in 1940. Meanwhile, the biggest rival news syndicate, the Chicago Tribune-New York News Syndicate, carried the Dick Tracy strips, which Republic adapted in 1937, with sequel serials appearing in 1938, 1939, and in 1941 (Los Angeles Times, 1937b). ${ }^{38}$ The same syndicate also offered Buck Rogers comics in Sunday supplements (turned into a film serial by Universal in 1939), and it ran a comic adaptation of Tarzan, the cross-media character having appeared in serials since 1920 (Los Angeles Times, 1937a).39 During their golden age, film serials indeed struck gold by exploiting the comic strips of the day.

These comic strips were themselves cross-media endeavors before being tied up with film serials. In addition to their radio serializations, they appeared as printed volumes, and they offered a variety of extra-textual advertising paraphernalia. ${ }^{40}$ However incidental the commonality, sound

37 Similar comic strips would have appeared in other newspapers of the King Features Syndicate. 38 Additionally, RKO released four DICK TRACY features between 1945 and 1947, followed by an ABC live-action television series in 1950/1951.

39 Tarzan serials include The Son of TARzan (Howells, 1920), The Adventures of TARzAN (Weiss, 1921), TArzan the Mighty (Universal, 1928), TARZAn the Tiger (Universal, 1929; see also Denson 2008), TARZAn the Fearless (Lesser, 1933), and The New AdVEntures of TARZAN (Burroughs-Tarzan Enterprises, 1935).

40 At the time, the Whitman Publishing Co. printed select comics' panels alongside explanatory sentences for child readers in 'Big Little Books', which featured many characters from comic strips and film serials, for instance Ace Drummond, Flash Gordon, Tim Tyler, and Dick Tracy. A later series called 'Better Little Books' carried CAptain Midnight. For Dick Tracy / Dick Tracy Returns, Whitman also published the 'Big Big Book', a cartoon book, a detective game, a card game, and a picture puzzle. 
serials of the form's golden era drew on nationally syndicated newspaper material, thus relying on the same cooperation that had marked the serial craze of the mid-1910s. Whereas in the earlier period, studios supplied the stories that were elaborated upon in the newspapers, now the newspapers provided the stories, or more often just the protagonists. Publicity suggestions reference this cross-media context as a means of advertising. The pressbook for FLASH GORDON, for example, features a written statement intended for a radio announcement, saying:

Millions of people throughout this country believed they had found the thrill of the century when they first saw Flash Gordon's adventures in the newspapers. They became enchanted by the colorful drawings and the narrative originated by Alex Raymond, the successful young artist whose work has gained wide acclaim for him. Now there is a greater thrill awaiting everybody in this city. "Flash Gordon" will be shown at the theatre on .$^{41}$

Similarly, a pre-formulated radio announcement for TIM TYLER'S LUCK informed audiences that the character now appeared in film theaters; ${ }^{42}$ Republic used panels from 'Dick Tracy' to advertise the serial in their yearbook; and the pressbook for SECRET AGENT X-9 recounted the biography of Charles Flanders, who drew the comic strip. The same pressbook also carried a list of the larger city newspapers publishing the comic. ${ }^{43}$ Film serial advertising thus played up the coterminous appearance of such stories and protagonists across the media, establishing a referential network that reassured their presence in the life-worlds of consumers.

As in the silent era, this emphasis on presence is not confined to cross-media synergies, but a similar presentism informs the film serials themselves. In addition to the presentism resulting from each episode's identification of a narrative past and future, sound serials stress a sense

41 Local exhibitors were meant to insert their own theater names and play dates in the blanks. 42 A similar suggestion appears in the pressbook for ACE DRUMMOND. Ads in local radio channels also announced serials with no corresponding program, such as HoLT OF THE SECRET SERVICE.

43 Similar reference to the newspaper strips appear, for instance, in the pressbooks for ACE Drummond (Universal, 1936), Dick Tracy Returns (Republic, 1938), and Mandrake the MAGICIAN (Columbia, 1939). Similar lists of radio stations airing a certain radio serial recur, for instance in the pressbook for DICK TRACY RETURNS. Whereas most serials capitalize on their drawn sources, the pressbook for RADIO PATROL almost entirely omits the fact. In this case, however, the serial itself begins each episode showing a boy on a couch reading comic strips. 
of presence in their showcasing of communications mechanisms and a concurring fascination with liveness, which will be explored in more detail in chapter six. Diegetic radio mechanisms, such as in THE VANISHING LEGION or in ACE DRUMMOND, as well as televisual communication in serials like The Clutching HAND or SPy SMASHer establish multiple narrative threads as taking place simultaneously. They thereby add complexity through a layered present tense. THE CLUTCHING HAND in fact alludes to the presentist grammar of intertitles in silent serials: in the serial's final chapter, detective Craig Kennedy notices being spied upon and informs his journalist sidekick Walter Jameson and the viewers in a written message that 'someone is listening' (episode 15, 'The Lone Hand'). This presentism is furthermore fostered by a crime plot that unfolds alongside its detection. Its narrative organization resembles the hard-boiled detective novels of the late $1920 \mathrm{~s}$ and 1930s, but crime plots informed film serials and their related written narratives from the beginning, at least since THE EXPLOITS OF ELAINE in $1914 / 15$. The crimes investigated in these stories always add up throughout the narrative, as opposed to a more classical, retrospective detection. ${ }^{44}$ Film serials in fact display an overall suspicion of the possibility of a sincere interest in the past, which surfaces in their representations of archeologists. In Plunder (Pathe, 1923), for instance, a treasure hunter who found diamonds in a 350-year-old cave consults a specialist at New York's American Museum of National History, where he is informed exclusively about their monetary value instead of about their history (episode 1, "The Bandaged Man'). Similarly, archaeologists in The Phantom Empire (Mascot, 1935) and Ace Drummond (Universal, 1936) only pretend to research history in order to conceal their endeavors to secure access to valuable natural resources. Instead of an interest in history, these characters pursue financial rewards that would benefit their present existence rather than informing mankind about the past.

Stories of crime and detection not only unfold around the diegetic investigators over a serial's run; they similarly surround viewers through elaborate marketing strategies that seem to extend a serial's narrative world beyond the confines of the cinematic frame. Pressbooks for serials at the time typically included numerous suggestions for 'ballyhoo', that is, for gimmicks to advertise a serial in the cinema, in front of it, and in a town more generally. If carried out, these suggestions would turn a small town's

44 The distinction between retrospective, 'Sherlockian' detection and 'hard-boiled' detective methods has been described by Tzvetan Todorov, and it has been recently explored in a history of the detective drama on US television by Mareike Jenner (Jenner 2016; Todorov 1977). 
main street into a serial fairground. ${ }^{45}$ Especially independent cinemas 'had become well established as an integral part of the local retail economy, recognized by other merchants as a "decided asset to town" in either securing an increasing share of consumer trade, or preventing the departure of that trade to larger towns' (Maltby 2013: 140). ${ }^{46}$ The pressbooks regarded their target exhibitors accordingly, treating them as local advertising agents and encouraging them to cooperate with neighboring businesses, ${ }^{47}$ local institutions such as schools or the police, ${ }^{48}$ or already existing clubs and societies. ${ }^{49}$ Additionally, almost every pressbook encouraged the exhibitor to form a local club to organize the children. Clubs held weekly meetings at the cinema, and each child received a membership card to be stamped for

45 Ballyhoo was by no means new at the time but dates back to nineteenth-century brass band parades that were held for occasions like store openings or stage production premieres. For ballyhoo in the nickelodeon era, see Altman 2004: 126-131.

46 When the increasing sale of cars enabled patrons to travel to larger cinemas, thereby threatening local houses in the early 1930s, the Chamber of Commerce in a town in Texas even lent its cinema the money to wire for sound, because losing the theater would hurt the town's commerce more generally (Gomery 2005: 94).

47 The pressbook for MANDRAKE THE MAGICIAN suggested placing window displays at newsstands carrying the magazine version of a comic strip, having local novelty stores sell the magic tricks and puzzles, partnering with local bread or milk companies on a coupon system, and asking men's and women's apparel and department stores to arrange stills of well-dressed stars in their windows. CAPTAIN MIDNIGHT suggested cooperating with men's apparel shops, jewelry stores, and ice cream parlors (which should invent CAPTAIN MIDNIGHT sodas or sundaes). Other examples include cooperation with Plymouth car dealerships for DiCK TRACY RETURNs (matching the serial's product placement), department and toy stores 'selling microscopes, chemical and scientific equipment sets for amateurs' for SECRET AGENT X-9, and cooperation with 'dealers in short wave receiving sets' for RADIO PATROL.

48 For MANDRAKe the Magician, theaters could cooperate with local libraries who offered books on magic. Cooperations with the police included invitations to officers to attend the initial episodes of Dick Tracy Returns and Holt of the SECRET SERVice as well as an audience address by the police chief for CAPTAIN MIDNIGHT, for which kids could also vote for their favorite policeman as their 'local "Midnight”'. CAPTAIN Midnight's, pressbook also suggested having the Red Cross or a 'civilian defense organization' lecture the audience, especially children, on 'the impending dangers of war', defense, and first aid. CAPTAIN AMERICA suggested ads in YMCAs and in schools. Similarly, DiCK TRACY RETURNS offered book covers for distribution in schools.

49 The pressbook for FLASH GORDON suggests cooperating with the local boy scouts. In the cae of Dick TRACY RETURNS, the pressbook referenced the radio program and its affiliated club, the Dick Tracy Secret Service Patrol. The club was attached to the serial's biggest sponsor, Quaker Oats, who had a mailing list of the club members. For CAPTAIN Midnight (1942), the pressbook suggested cooperating with the 'Junior Aviator Organization', a club sponsored by the Scripps Howard newspaper chain, and CAPTAIN AMERICA (1944) suggested contacting the comic's 'Captain America fan club'. MANDRAKE THE MAGICIAN suggested contacting adult 'clubs and societies of magicians, both professional and amateur'. 
each attended screening..$^{0}$ Clubs would also hold contests, as in the case of MANDRAKE THE MAGICIAN, the pressbook for which suggested 'smartest magician contests, contest for the best original trick or illusion, best essay on magic etc.'

Whereas such marketing stunts resemble practices of the 1920s, now the serials were based on comic heroes already circulating in newspapers and radio shows, and the studios had already arranged some larger co-operations with major business partners, especially for toys. ${ }^{1}$ Pressbooks nevertheless encouraged local advertising, urging exhibitors in whose town a corresponding comic strip was published in the newspaper to buy ad space on the same page or to obtain ad space in exchange for advertising the newspaper at the cinema. ${ }^{2}$ Exhibitors were also encouraged to pass along additional material to newspapers, such as reviews, feature stories, or contests, which would award, for example, the best detective short story for DICK TRACY RETURNS (Republic, 1938) or the best job of coloring the black and white newspaper strips of MANDRAKE THE MAGICIAN. The result is a mix of national and local advertising, in which the individual exhibitor's 'ballyhoo' transformed the consumption of a mass-marketed product into a local experience. Nevertheless, despite the pressbooks' encouragement of such individual adjustments of national campaigns to local needs, such efforts also needed to be kept at bay to avoid alienating the national sponsors. In their 1937-1938 Yearbook, Republic for instance pressured exhibitors of THE LONE RANGER (Republic, 1938) to okay the announcement of the serial in local radio stations with the respective sponsors of the radio program for that region. The studio additionally noted that 'any local commercial tie-ups except with licensed companies' were strictly prohibited. Therefore, while encouraging maximum publicity on a local basis, studios were struggling to keep these individual efforts from interfering with their cross-national campaigns.

The extent of the local marketing stunts is probably most visible from the pressbooks' suggestions for lobby decorations and 'street bally'. If,

50 Clubs include the 'Ace Drummond Junior Pilots', the 'Captain Midnight Adventure Club', and 'the Captain America Club'.

51 FLASH GORDON offered toy ray guns, play suits, pop-up books, sponge rubber balls, coloring books, and metal toy casting models. MANDRAKE THE MAGICIAN cooperated with a toy company producing the Mysto Magic set. Dick TraCy RETURns' pressbook lists, for instance, tie-ups with Quaker Oats (box tops could be exchanged for Dick TRACY toys) and with manufacturers of DicK TRACY pocket knives, raincoats, wrist watches, a Siren Pistol and Target Game, a ventriloquist's doll, a Dick TrACY military brush set, flashlights, moccasins, coloring and printing sets, singing lariats, model rocket space ships, and toy 'bang guns'.

52 Such suggestions occur, for instance, in the pressbooks for FlaSH GoRdon, ACE DRUMmOND, and Mandrake the Magician. 
hypothetically, a theater owner followed the pressbook suggestions meticulously, his or her lobby would have been transformed entirely along the lines of the serial the cinema was currently running. There were posters, displays, cut-outs, and lobby cards to be ordered for every serial. Most serials suggested additional lobby stunts, for instance the placement of a working Dictaphone - that is, a microphone and receiver to be wired across the lobby-for MANDRAKe the MAgician; for ACE DRUMmond, a model or real airplane in the lobby, with a hidden speaker and a theater employee talking to people in the plane without being seen; a large, clock-faced wheel of fortune that awards a prize if it stops at midnight for CAPTAIN MIDNIGHT (Columbia, 1942); or an exhibit of 'the various arms and ammunitions used by gangland' as a stunt for Dick TRACY RETURNs, in co-operation with the local police department. ${ }^{53}$ For FLASH GoRDON, the lobby could include a big drum hanging from the ceiling (building instructions suggested in the pressbook), with a theater employee costumed as a warrior from the serial striking 'it with heavily padded stick at frequent intervals' (pressbook), or a similarly home-made magic mirror on which posters of the serial become visible and invisible at intervals. Moreover, the lobby could also include a booth where a uniformed policeman takes the fingerprints of children and adults-a stunt suggested for SECRET AgENT X-9.

The street in front of the theater would similarly have been adapted to the serial, featuring a parade, costumed characters, ${ }^{54}$ or, in the case of Dick Tracy Returns, a sedan with posters on the sides, "loaded with tough-looking individuals' (pressbook). It seems as though the idea behind these suggestions for ballyhoo was to create an immersive film experience, but not by immersing viewers in the story depicted on screen. Instead of drawing us in, film serials reach out to us. The pressbook for FLASH GORDON captured this idea of making the neighborhood part of the film experience when it offered helmets to be ordered directly from the studio as give-aways to children before the screening. The pressbook promises that 'your neighborhood will look like a little planet "Mongo" when you give them away with the FLASH GORDON pistol!' Instead of asking viewers to imaginatively join the world on screen - the kind of immersion idealized in Sherlock, Jr. (Metro Pictures, 1924) when Buster Keaton

53 A similar stunt was suggested for Holt of the SeCret Service. The police should exhibit 'police laboratory paraphernalia' and 'a real rogues' gallery, wanted poster, fingerprint apparatus, guns, tear gas bombs, etc.' (pressbook).

54 For parade suggestions see, for instance, FLASH GORDON's pressbook; for costumed 'perambulators', see the pressbook for CAPTAIN MIDNIGHT. 
enters a projected film - film serials literally took over and transformed the whole theater, and-ideally - a town's main street, establishing the continued spatial and temporal presence of a given serial in the daily lives of its viewers.

\section{Serials are Presentational: Mechanical and Narrative Process}

This 'reaching out' similarly registers on the screen itself. Film serials are radically presentational, that is, they present their attractions and their narratives just like local exhibitors present an airplane in the lobby or a poster in a local department store. Serials frequently showcase and comment upon their own narrative organization, they self-reflexively address their mediality, they insist on spectacular stunts, and they refuse to distinguish clearly between actors and characters, or more generally between the worlds on and off screen. Such a notion of presentationalism appears prominently in Matthew Solomon's reading of The MASTER Mystery (Octagon, 1919), which I will detail before mapping various presentational methods of storytelling from the earliest serials to the golden-era classics.

THE MASTER MYstery showcases the popular illusionist and escape artist Harry Houdini in the role of Quentin Locke, a scientifically versed detective. He enters a company called International Patents, Inc. as a secret spy to uncover their agenda of purchasing inventions in order to suppress them, to the benefit of already established rival businesses. ${ }^{55}$ This storyline serves as a framework for the portrayal of Houdini's spectacular escape stunts. Solomon argues that this staging of the magician's stunt work transfers the performative style of his stage shows to the film screen. As a result, the serial focuses on 'presentational modes of performance - modes of performance that accomplish or demonstrate something, often something wonderful or marvelous - and not on representational modes of performance like

55 The serial's explanation that Locke is collecting 'evidence for conviction under the AntiTrust Law' (episode 1, 'Living Death') can be read as a critical comment on the state of the film business at the time. The Motion Picture Patent Company (also called the 'Trust'), which had controlled film production through the licensing of patented technical equipment up to 1913, had increasingly weakened until its dissolution in 1918 (Curtis 2004: 257; Maltby 2003: 560; Sklar 1994:142). Meanwhile, the independent studios opposing the trust were forming monopolies of their own. Famous Players-Lasky, for instance, integrated production and distribution in 1916 and created an exhibition chain of more than 600 theaters named Paramount between 1919 and 1921 (Sklar 1994: 143-146; Tzioumakis 2006: 25-27). In 1919, the monopolization of the film industry was thus looming large. The recurrence of anti-oligarchic themes in serials, for instance in THE POWER GOD (Goodwill, 1925), may be related to their concentration in independent companies. 
acting, which simulates the actions and interactions of characters' (2010: 8 ; italics in the original). The serial's noteworthy stylistics result from its efforts to prove the legitimacy of Houdini's stunts: advertisements at the time promised that the serial would portray the illusionist's feats by filming them in a single take (Solomon 2010: 111-112). This promise is both an acknowledgment of and a response to the fact that the filmic medium itself has the capacity to create magic stunts cinematically, without the prowess of a magician or escape artist. After all, magicians such as George Méliès used film to demonstrate their physical artistry but also made use of the medium's capacity to produce marvels through montage and mise-en-scène (p. 2).

In Solomon's view, The MAster Mystery fails to deliver these unusually long takes; nor does it reveal Houdini's secrets (pp. 111-112). However, this failure may result from censorship practices that aimed to limit the serial's didactic presentation of, for instance, how to pick locks. For a re-release in New York in 1924, for example, the serial was placed under consideration of the state's censor board. In addition to too violent or gruesome visuals, the board in particular demanded that scenes that 'tend to incite to crime' be cut. Such scenes included, for instance, the very detailed depiction of Houdini employing pieces of an umbrella to unlock a door that is bolted on the inside. ${ }^{5}$ As the serial's initial release coincided with the increased censorship of serials across multiple states, it is likely that other states similarly censored The MAster Mystery. As with any serial of the time, fans across the nation saw substantially different versions of the film depending on where they lived. The chapters originally placed under consideration with the review boards, however, were detailed enough to arouse the suspicions of the censors, and the rare occurrence of long takes in The Master Mystery may have been the result of censors' demands to eliminate aspects of the stunts. Nevertheless, the version of the serial that is available today does include some unusually long takes in the second episode, which shows Houdini's escape from a straitjacket, and in the third episode, in which the magician frees himself from having been tied, in mid-air, to a coat hanger by unlocking and opening a door with his toes and propping up his weight on top of it (episode 2, 'The Iron Terror'; episode 3, 'The Water Peril'). The serial's claim to present Houdini's feats

$5^{6}$ This information on censorship is included in a special feature in the 2008 release of THE MASTER MYstery as a part of Kino International's three DVD collection Houdini - The Movie Star. A majority of the serial's footage as it is available today has been reassembled from previously edited and censored material. 
rather than create them through editing and cinematography therefore impacted the filmic style of the episodes, and it similarly informed the magician's later films.

Reviews of the features that Houdini filmed in 1919 and 1920 scorned the films as being merely condensed serials (Solomon 2010: 7, 110). Whereas Solomon considers this rejection a result of the serial's prioritizing of sensations and stunt work over psychological depth, the reason could just as well be the presentational mode of storytelling itself. ${ }^{57}$ Rather than resulting exclusively from Houdini's background in stage entertainment, the presentational quality is shared by a majority, if not all film serials of the time. However, whereas The MAster Mystery's presentationalism strives to counteract accusations that Houdini's stunts were mere cinematic creations, other serials are presentational because they self-reflexively foreground the cinematic 'created-ness' of their stories. Throughout the silent and sound eras, film serials negated representational self-containment and articulated their character as filmic creation instead. As the following analyses will illustrate, the serials' presentational mode of storytelling registered in self-reflexive statements, expressionist montages, overt repetitions, and trick cliffhangers.

The Perils of PAUline (Pathe, 1914) rather overtly presents its story to an audience instead of inviting a more immersive kind of reception. Each episode rehearses the serial's formula, that is, a new plan by the villain Koerner to murder Pauline and her subsequent rescue by her fiancée, in a new thematic or generic setting such as the Wild West (episode 2, 'Goddess of the Far West'), a maritime theme (episode 3, 'The Pirate Treasure'), car racing (episode 4, 'The Deadly Turning'), or aviation (episode 6, 'The Shattered Plane'). As a consequence, the viewers' interest in upcoming installments concerns new thematic settings or featured death traps rather than plot development. For the producers, the formula allowed for the addition of almost endless episodes. In an article that eventually points to the advantages of the self-contained episodes of Lubin studio's THE BELOVED ADVEnTURER, the Washington Times highlights the ongoing nature of THE Perils of Pauline:

57 Houdini's two subsequently produced independent films threaten to be understood solely as failures in Solomon's study (2010:111). However, Houdini's return to independent production and States Rights distribution could also result from the belief that through these release channels, the films reached an audience that was open to the presentational approach as opposed to audiences who frequented theaters of integrated chains and were used to studio-era representational filmmaking. 
"The Perils of Pauline," is very frankly an endless affair, the producers admitting that they will keep their heroine skipping from one adventure to another as long as the public evinces a liking for her. [...] practically everyone who sees one of the pictures [of THE BELOVED AdVENTURER] will want to see them all. But the point is that it is not absolutely essential, as is the case with "The Million Dollar Mystery," the very best of the straight continued-in-our-next types. (Washington Times)

THE PERILS OF PAUline thus showcased a similar schema in varying settings, propelling onwards like a narrative machine that churns out new incarnations of the same model or type. In its reference to THE MiLlion Dollar MYstery, moreover, the quote from the Washington Times mentions that other serials did not follow PAULINE's exact formula ${ }^{5}$ but replaced episodic self-containment with an ongoing narrative and cliffhanger endings. All serials range on a scale between episodicity and an ongoing narrative flow; however, an individual serial would determine the interdependence of its episodes and then continue with its strategy throughout its run, that is, all episodes of one serial would use cliffhangers or none, individual actors would be introduced in each episode or in none at all, etc. Each serial thus adopted a structure and made it visible through its weekly reiteration. In short, serials exhibited narration as narration by serially reinforcing a similar structural framework in each episode.

Shane Denson sees a similar exhibition of narration at work in THE PERILS OF PAULINE as it showcases narration as an attraction, just as the filmic medium was an attraction in the first decade of film. The serial highlighted the principles of storytelling that later became invisible but that were nevertheless constitutive of narrative cinema, and it reinforced these principles through 'practice, repetition and drilling' as enabled by the serial form (Denson 2014b: 72; cf. Enstad 1995; Gunning 1986). The serial thus bears a 'demonstrative function, as if the films are pointing out to viewers: "This is how we construct a story"' (Denson 2014b: 72). Serials thereby complicate the differentiation between narration and monstration: between telling a story and showing it. The serial—which is itself a 'showing/telling vehicle'—shows how it tells a story (Denson,

$5^{8}$ The exact structure of the episodes of THE PERILS OF PAULINE is difficult to ascertain today, as the available serial is a nine-chapter condensation of the original twenty chapters for a European market (Singer 2001: 322, fn39). Shelley Stamp compares two reviews of the same episode of THE Perils of PAUline, which indicate that although each chapter was self-contained, one of the reviewers had attended a screening of reel two of an episode and reel one of the following one, which repurposed the mid-episode climax as a cliffhanger (2000: 119). 
2014b, pp. 74-75). Adding another layer of presentationalism, The Perils OF PAULINE pinpoints its own demonstrative function when diegetic characters comment on the narrative. When the culprits enlist an old sailor in a plan to kill Pauline in episode three, they point to the sailor and say 'here's an interesting looking character we can use in our plan'. The maritime character then proceeds to relate some tall tales to Pauline, which are shown within the narrative, essentially exemplifying how stories are told within film (episode 3, 'The Pirate Treasure'; Denson 2014b: 74-75).

Similarly self-reflexive comments on the narrative content and formula of serials recurred throughout the silent era, especially in Pathe's Pearl White vehicles. In the World War I preparedness serial PEARL of THE ARMY, for instance, Pearl Dare (Pearl White) hunts a spy within the armed forces. A high-ranking military official eventually exclaims in front of his soldiers that 'I want some action, all this talk about a "Secret Menace" is juvenile!' (episode 6, 'Major Brent's Perfidy'). While explicitly addressing the delay in the defense plans for the Panama Canal, the statement also highlights the frequency of villainous characters in serials and the fact that Pearl's hunt for the 'Secret Menace' postpones the serial's military action. A similar foregrounding of narration appears from intertitles that direct questions at the audience, such as before the reel break in episode four: 'What mysterious power brought all those involved in the defense plans together again, under such strange circumstances?' ('War Clouds') — a strategy that is mostly reserved for chapter endings.

Comparable instances appear in Plunder (Pathe, 1923), in which protagonist Pearl Travers (Pearl White) comments on the frequent appearance of mysterious, secretive characters ${ }^{59}$ coming to the aid of serial queens when she tells her lover: 'Now don't make one of your usual exits, forgetting to come back: or I'll know you are just a Man of Mystery and not a Romantic Hero after all!' (episode 9, 'Game Clear Through'). In fact, PLUNDER's presentational approach to storytelling repeatedly resorts to the insertion of non-diegetic cutaways to provide metaphoric commentary or explanation. In the initial episode, for instance, a thief attempts to evade capture by changing cars as they run parallel on New York's streets. The film then inserts a close-up of a shell game to explain the thief's approach.

59 The unknown rescuer also appears, for example, in The Iron Claw (Pathe, 1916), The Hope Diamond Mystery (Kosmik, 1921), and in The Timber Queen (Roland, 1922). 

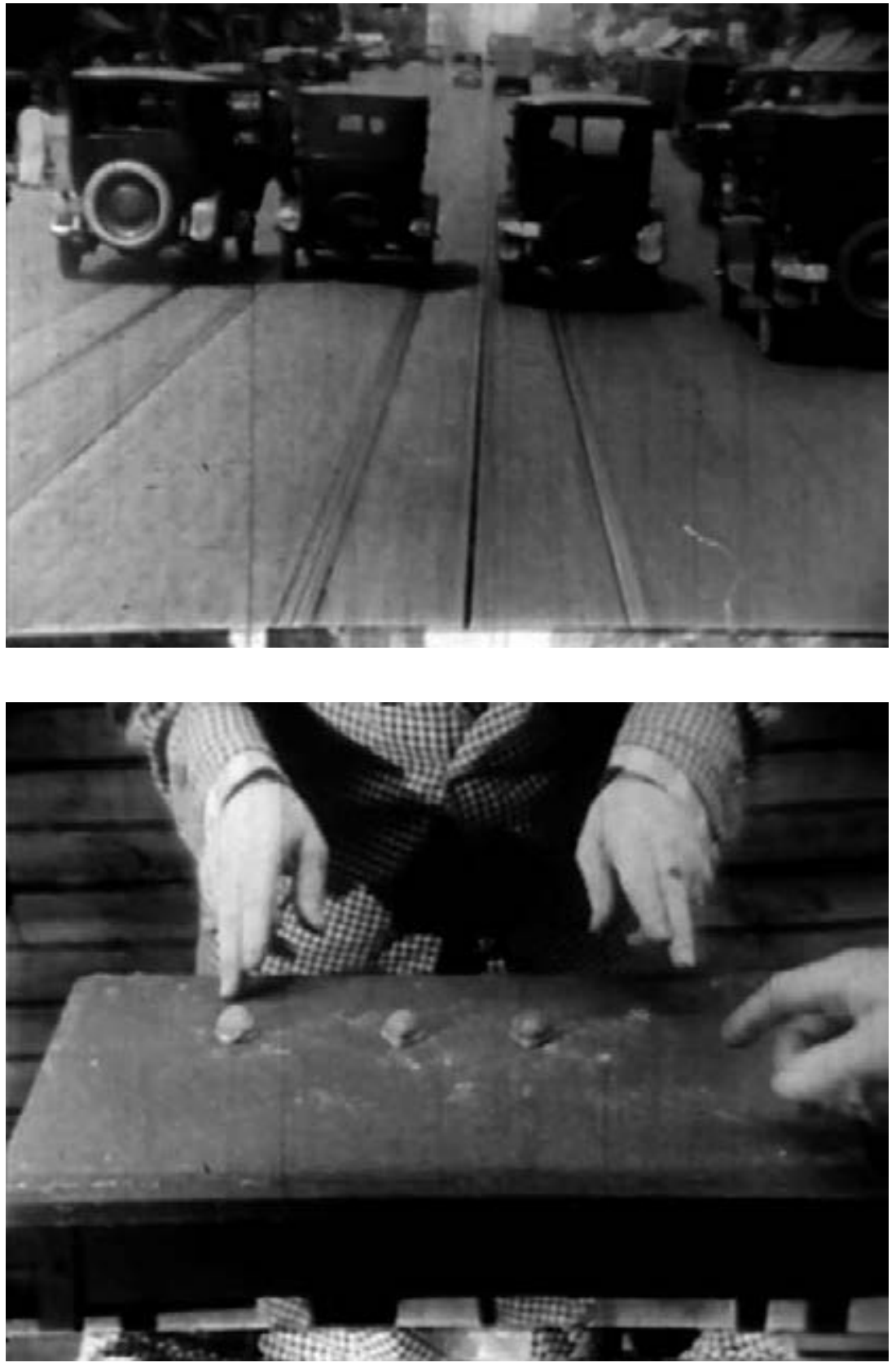

4., 5. Two shots from Plunder (Pathe, 1923), episode one, 'The Bandaged Man'. In the first shot, a thief switches from the car on the left to the car on its right-hand side. 
Similarly, the same episode inserts shots of a snarling dog to emphasize the anger felt by Travers' nemesis Jude Deering (Harry Semels) (episode 1, 'The Bandaged Man'). The following chapter visualizes Travers' nightmare of a character she falsely believes to have murdered in an expressionistic dream sequence. Moreover, PLUNDER continuously adds images and superimpositions to visualize a characters' thoughts and inner emotional states. Thus, when Travers and Deering competitively bid for stock of a downtown high rise, the treasure they believe to be buried underneath the building is superimposed between their heads, resembling a thought cloud in a comic book's panel (episode 5, 'To Beat a Knave'). Two episodes later, Deering, who at this point is believed to be responsible for Travers' alleged death, sees her figure superimposed into various settings three times (episode 7 , 'Mocked from the Grave'). In this instance of unusual psychological depth, PLUNDER presents Deering's moral conflict by means of including visuals that are not physically manifest in the verisimilar filmic world.

Whereas similar elements did occur in classical features, their accumulation in this serial is nevertheless noteworthy, particularly when considered

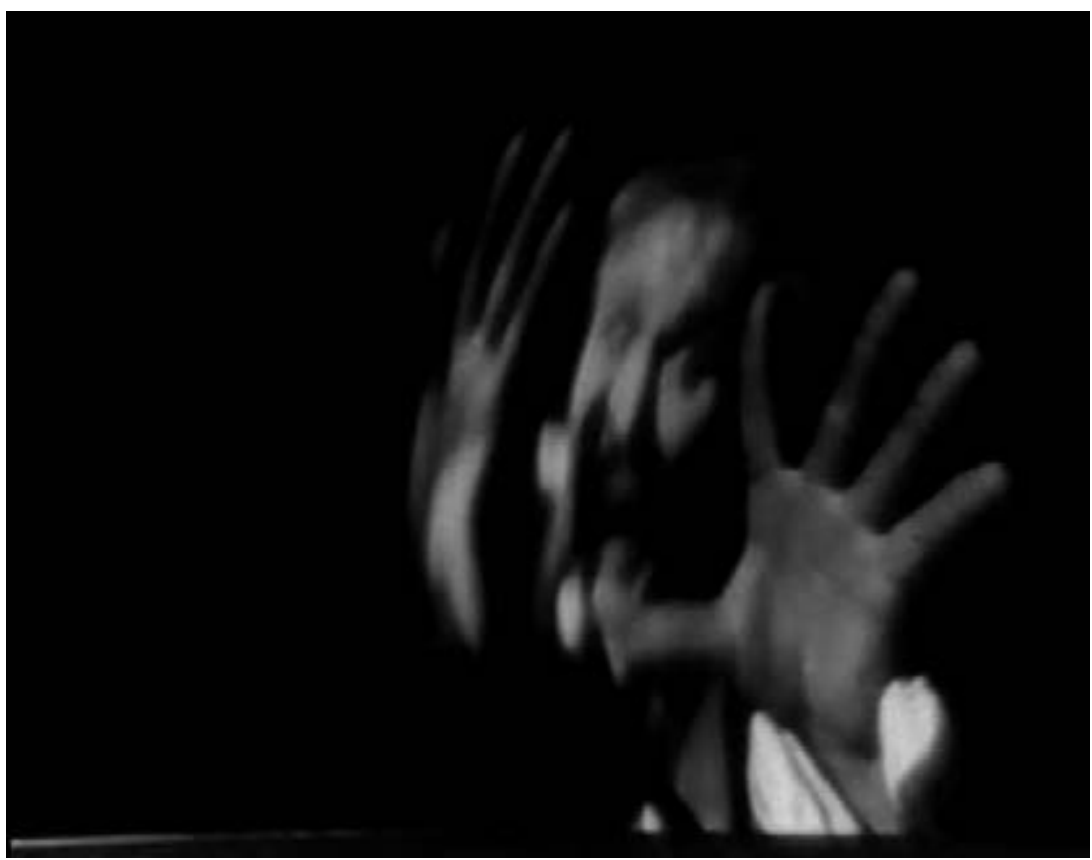

6. Film still from Pearl Travers' dream in Plunder (Pathe, 1923), episode 2, 'Held by the Enemy'. 
in the light of Denson's identification of the serials' prolonged transitional status. Produced in 1923, when the classical style was firmly implemented, PLUNDER exemplified what Denson considers the non-teleological, contradictory transitional status of silent-era serials: despite their help in training audiences for the classical paradigm, they refused to adhere to such a paradigm themselves (2014b: 72-73). Part of the issue at stake, I contend, is that film serials emerged from a transitional-era background in which they may have served to train an audience, but they outlived their transitionalera function. Serials consolidated into a form that continued to exist past World War II, and all through that time, they continued to demonstrate and present narration in ways that seem to outdo contemporaneous features.

\section{Presentational Storytelling and the Operational Aesthetic}

In addition to such minute, overtly self-reflexive instances, the presentational mode of address manifests itself in the focus on process that is shared by many serials. Their operational aesthetic casts the observation and tracking of processes as a pleasurable activity in itself. This appreciation helps to explain the viewers' continued interest in film serials and their concurrent willingness to partake in the kind of training that serials offer. The operational aesthetic of film serials is marked by the presentation of both narrative and technical processes as they interrelate. Such technical processes moreover include both mechanisms that are displayed on screen and film itself as a mechanism. This aesthetic of the operational surfaces repeatedly in a number of film serials — in fact, in a majority of those that survive. It is particularly evident in scenes that insist on the Goldbergian nature of the death threats against a serial's respective protagonist. In the following, I will point to the different shapes these scenes, and the operational aesthetic, can assume based on a number of examples.

Many of the technical mechanisms shown in film serials serve to delay the threat of the protagonist's death. In ZudorA (Thanhouser, 1914), ${ }^{60}$ for instance, the eponymous serial queen's (Marguerite Snow) love interest, John Storm (Harry Benham), is held captive in a chamber with bolted steel walls. Outside of the room, a henchman of the serial's evil mystic tribe turns a strong wheel to operate the contracting walls of the chamber that

6o Episode two, 'The Secret of the Sleeping House', is the only episode of Zudora known to remain. It is available for online streaming at http://thanhouser.org. For more information on the serial's framing story, see Singer 1993: 497-499. 


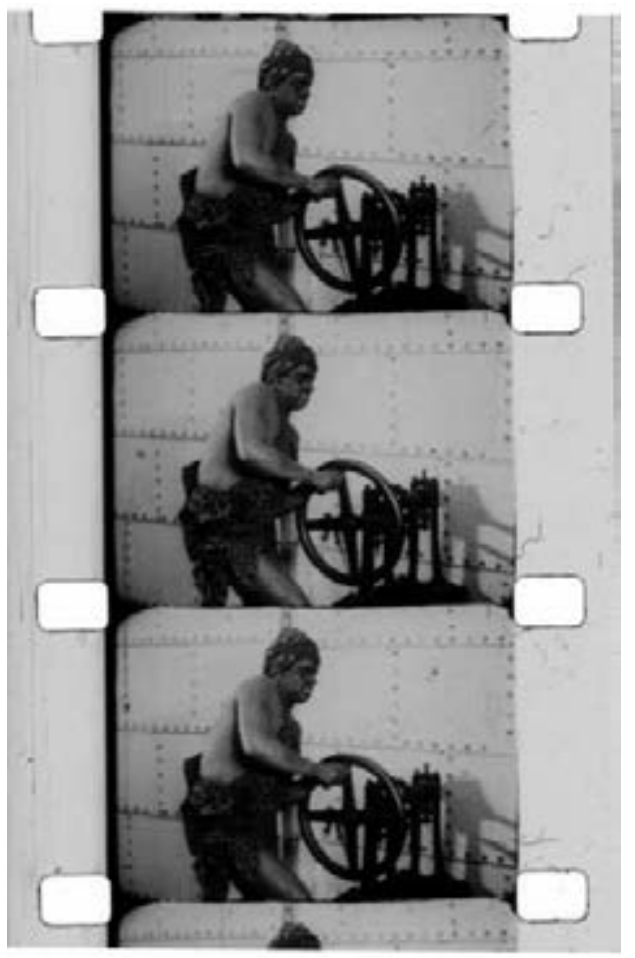

7. A character operating the contracting chamber in Zudora (Thanhouser, 1914), episode two, 'The Secret of the Sleeping House'. Image Credit: Thanhouser Company Film Preservation, Inc.

threaten to crush John inside. Scenes of the henchman outside and John inside are interspersed with Zudora's rush to rescue her lover, who, as an interesting twist on gender stereotypes, faints in her arms when rescued. The contracting chamber serves to both visualize the impending doom and delay John's death (ZudorA, episode 2, 'The Secret of the Sleeping House').

The creation of suspense by means of parallel editing and the delay of action is a stock element of the melodramatic mode of storytelling, which informs American film in general and film serials in particular (L. Williams 1998; Kelleter, Mayer, and Krah 2007; Singer 2001; Higgins 2016). This scene from ZUDORA visualizes a melodramatic delay of action in the form of a mechanized threat, employing a modernist imagery that differs radically from the mise-en-scène of the religious temple in which the contracting chamber is located. In fact, most other scenes in the episode are set at the temple, which is stuffed with ornamental drapery, lotus leaf plants, and religious idols, or in the similarly cluttered settings of late-Victorian homes. The inside and outside of the contracting chamber, by contrast, feature bright backgrounds, accentuated 
lines, and an industrial aesthetic of steel bolts and handles. This visual contrast underlines the function of the contracting chamber as a machine that animates the film's melodramatic suspense. Moreover, it re-situates the serial's mystic plot firmly in the context of twentieth-century modernity: The image of the henchman as depicted is comparable to later images of machine operators such as in Fritz Lang's Metropolis (1927) or in the late photography of Lewis Hine. This climax of ZuDORA's second episode thus inscribes modernity's machine aesthetic into the serial's mystic plot and mise-en-scène.

The melodramatic mode that informs especially the climactic endings of both cliffhanging and self-contained serial episodes is the result of the fact that we never see their mechanical contraptions function successfully. In melodrama, as Linda Williams explains, "'in the nick of time" defies "too late"' (L. Williams 1998; also quoted in Higgins 2016: 64): Serials place their protagonists in life-threatening situations and thus create suspense by suggesting that this time, they might meet their fate, only to have them once again escape in the last second. Film serials relentlessly repeat this formula although audiences know that the 'too-late' cannot possibly take effect as long as our heroes and heroines are scheduled to return in the following episode. The actual death of Elaine in the tenth episode of THE EXPLOITS OF ELAINE thus both takes the formula to an extreme and constitutes an ironic comment on it. In this case, the serial's male protagonist, the scientific Detective Kennedy, revives the serial-queen by electrical resuscitation after she has been declared dead by paramedics called to the scene (episode 10, 'The Life Current'). Twenty years later, Gene Autry dies in The Phantom EmpIRE's sixth episode and is brought back to life the following week (episode 7 , 'From Death to Life').

Notwithstanding such exceptions, the usual rescue 'in the nick of time' thwarts the successful operation of mechanical death contraptions, that is, they never truly kill any of a serial's characters. Nevertheless, suspense works on the pretense that mechanisms such as the contracting chamber could technically crush Zudora's love interest. The films need to convince audiences of the impending doom and of the functionality of the contraption. In order to do so, they document and exemplify the chains of cause and effect that make the mechanism work. A prominent example of this appears in THE EXPLOITS OF ELAINE, a forerunner of many stock scenes in film serials more generally. In episode four, the villain called The Clutching Hand (Sheldon Lewis) sneaks into Detective Kennedy's (Arnold Daly) apartment and sets up a death contraption, hiding a rifle in the fireplace and attaching a thin thread to its trigger. He attaches the other end of the thread to a portrait of Elaine (Pearl White) hanging crookedly on the wall. Whereas detailed close-ups of the mechanism suggest its functionality, it is the task of the audience to 
make the leap from cause to effect, that is, to understand that Kennedy will be shot as soon as his love for Elaine makes him look at the portrait and his fastidiousness makes him straighten the frame. That understanding always remains in the realms of the imagined, as Kennedy will not actually get shot: he has been alerted by his seismograph, which recorded that someone entered the apartment in his absence. Instead, Kennedy will reward our understanding of the mechanism by triggering it with an umbrella and thus demonstrating the effect of the machine. The moment of suspense, however, rested on the previous understanding of the threat (episode 4, 'The Frozen Safe').

Whereas this example from THE ExPLOITS OF ELAINE leaves the outcome of the chain of cause and effect to our imagination, other examples include a split-second instance before the episode ending that shows a mechanism's full effect, only to rewrite the scene in the following episode. In A WomAN IN GREY (Serico, 1920), for instance, in a scene that works without such elaborate chains of cause and effect, the heroine Ruth Hope (Arlene Pretty) has her adversary at gunpoint and walks backwards, attempting to make an escape. However, a second villain opens a trap door to a basement torture chamber below. The final frame of the episode shows Ruth taking one step too far and stumbling into the hole. In the following episode, however, she is still standing at its edge (episodes 8, 'The Drop to Death'; and 9, 'Burning Strands'). The cliffhanger ending thus includes frames that are invalidated the following week, but suspense nevertheless hinges on the earlier knowledge that Ruth might fall into the trap. Instead of causing an epistemological crisis for the viewer, such instances exemplify the serials' presentational address. Similar to the explanatory shots of the shell game or a snarling dog in PLUNDER, this mode of address includes shots that clarify information rather than solely portraying verisimilar action.

This filmic strategy rests on the more general approach to story time and shot relations of serials, which comes to the fore in another cliffhanger in A WOMAN IN GREY. Towards the end of episode nine, Ruth is held captive in a former clubhouse by the villain's henchmen, an elderly but nonetheless frightening couple. While Ruth is gagged and tied to a bed, the camera follows the old lady as she moves the bed underneath a concrete block that is dangling from the ceiling on a rope. Afterwards, the villainous witch moves a coffee table with a burning candle so that it is positioned underneath the end of the rope. Alternating close-ups of Ruth, the concrete block above her, and the candle slowly burning through the rope indicate that eventually, the rope will snap and the concrete block will crush Ruth.

The actual threat, again, results from the viewers' understanding of the relation between candle, rope, concrete block, and serial queen (episode 9, 

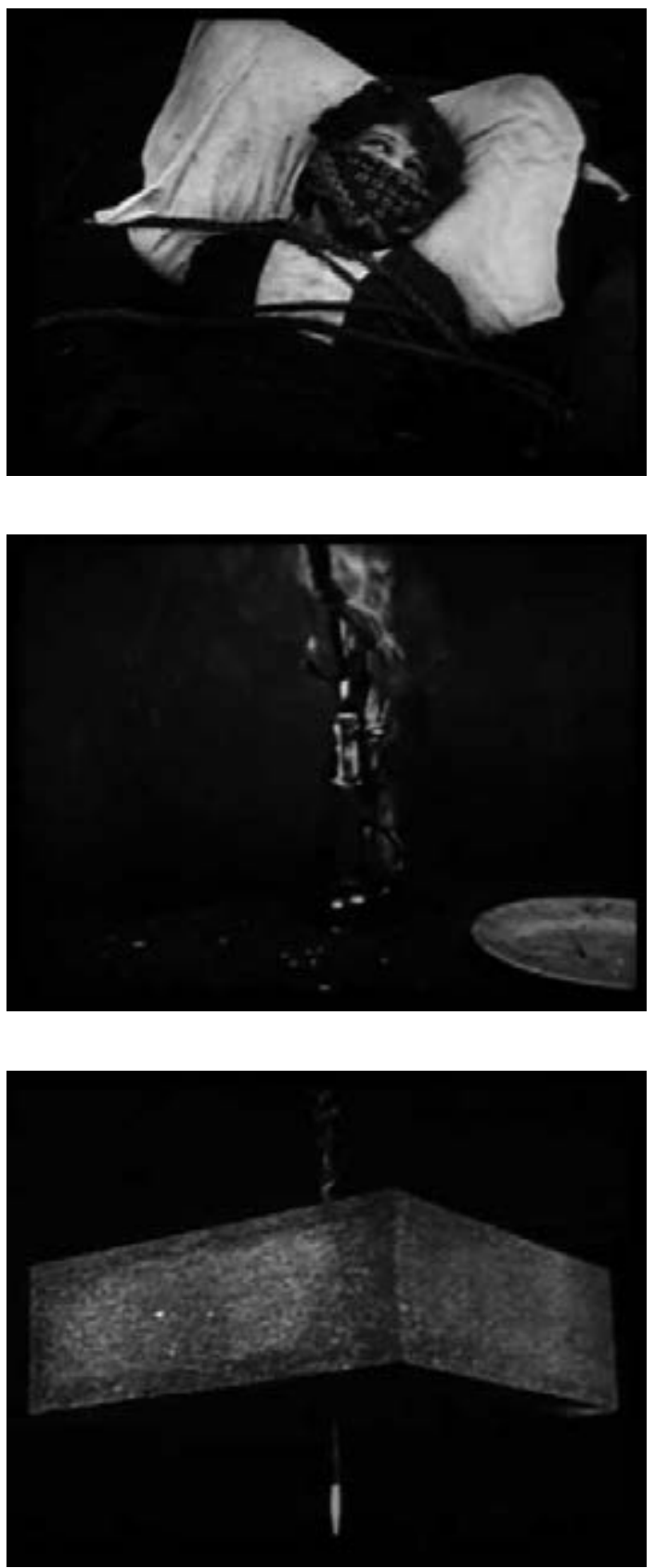

8.-10. Three successive shots from A WomAn In GREY (Serico, 1920), episode 9, 'Burning Strands', showing Ruth Hope (Arlene Pretty) bound and gagged, the candle burning the rope, and the concrete block with a pointed tip beneath it. 
'Burning Strands'). Although the following episode confirms the placement of the bed underneath the concrete block in a vertical panning shot, a few seconds later the concrete block surprisingly plunges to the ground besides the bed. In what Singer describes as 'the serial's characteristic temporal overlap and dubious narrative "rewriting"' (1996: 77), the episode further adds sequences of Ruth's rescue by another of the serial's numerous suspicious characters (episode 10, 'The House of Horrors'). Singer describes this incident as follows:

The cliffhanger's overlap structure also creates an uncanny feeling of epistemological insecurity. We see the same events twice, but we barely recognize them as the same spatiotemporal phenomena, since they have mutated and expanded. The serial is, in a sense, the idiot cousin of Cubism. By accident, and in complete ignorance of its phenomenological insight, it accentuates the subjective and fragmentary nature of modern perception. The world becomes perceptually fractured as the authoritative narration of one episode is destabilized in the next, as supposedly identical events are reconfigured in strange and incongruous ways. (p. 77)

If we re-read the same narrative instance in A WOMAN IN GREY as a presentation of a filmic operation, that is, as a staging of a chain of cause and effect, then the serial's foregrounding of fragmented perception may appear less accidental. The presented chain of cause and effect includes the candle, which burns the rope, which in turn holds - and threatens to cease holding - the concrete block. On another level, that chain of cause and effect is a purely cinematic creation: fragmented shots arranged in succession, whose relation results from editing. The operational aesthetic can describe an appreciation of both the contraption suggested diegetically and the cinematic sequence of images. However, the 'overlap structure' suggests that the appreciation lies with the latter: the cinematographic chain of cause and effect can expand indefinitely, and it can add parts to the chain or alter them. Singer is essentially proposing the same but under the assumption that the addition of events in the chain extends the length of time over which the action unfolds. But the serial, as I have established, is radically presentist. Rather than describing a succession of events, the individual shots depict things taking place at the same time. The operational aesthetic is all about expansion, about operations occurring over time without taking up time, which runs continuously in the present. This presentist focus allows for serials to highlight simultaneity-to showcase things taking place at the same time from various angles. Therefore, the serial does in fact adhere to a Cubist logic rather than constituting its 'idiot brother'. The mechanical 
angle of the operational aesthetic is thus twofold, as it applies to technical mechanisms and cause and effect chains in a film's setting but also to such chains as they result from editing and the Kuleshov effect. ${ }^{61} \mathrm{~A}$ similar kind of overlap structure came to be increasingly used throughout the silent era and was to become a stock feature of sound serials.

A logic of process and fragmentation also applies to broader plot structures that create suspense through multiple chains of cause and effect or 'what ifs'. A prominent example of this occurs in The Timber QueEn (Roland, 1922). In episode four, Jim Cluxton (Val Paul) takes Don Mackay (Bruce Gordon) hostage to prevent his marriage with Ruth Reading (Ruth Roland). Cluxton and his gang take Don to a shack and wire it with dynamite, so that it would explode if he attempted to escape. However, Don managed to leave a secret note for Ruth indicating his whereabouts. Fearing that Ruth will find him and cause the shack to explode, Don waits for two days in capture and holds his hand over an oil lamp to keep himself from falling asleep. Meanwhile, Ruth is on her way to the shack, and she is being pursued by Cluxton, who now aims to rescue her because he only wanted her unmarried, not blown to pieces (episode 4, 'Go Get Your Man'). This rather complicated set-up resembles the technical causes and effects of candle, rope, and concrete block in A WomAn IN Grey. In fact, Don's body appears to be quite physically a part of a mechanism. Repeated close-ups of the grossly burned skin on the back of his hand highlight the side-effects of using a candle to stay awake. Don's body thus corporeally enters the chain of cause and effect that, in the worst-case scenario imagined by the viewers, would cause his and Ruth's death in an explosion. Once again, the complex arrangement of 'ifs' and 'thens' in less than a single reel's length delays the action and enables the parallel editing of multiple activities taking place in multiple diegetic locations. However, they also engage the viewer in a mental activity where both the possible rescue in time and the 'too late' depend on the imaginative capabilities of the viewer. That imagination of what will happen, in turn, relies on close-up shots and detailed descriptions of process.

Jennifer Bean considers a similar insistence of corporeality in silent serials a means to counteract the standardized routines that increasingly informed transitional-era film production. She locates the practice of foregrounding the corporeal at the intersection of the films and their discussions in magazines and newspapers. Whereas film studios and the films themselves blurred the

61 Named for 1920s Soviet filmmaker Lev Kuleshov, the 'Kuleshov effect' describes the viewers' assumption that the elements shown in two consecutive shots exist in a shared space, which enables filmmakers to create spaces cinematically (Bordwell \& Thompson 2008: 227). 


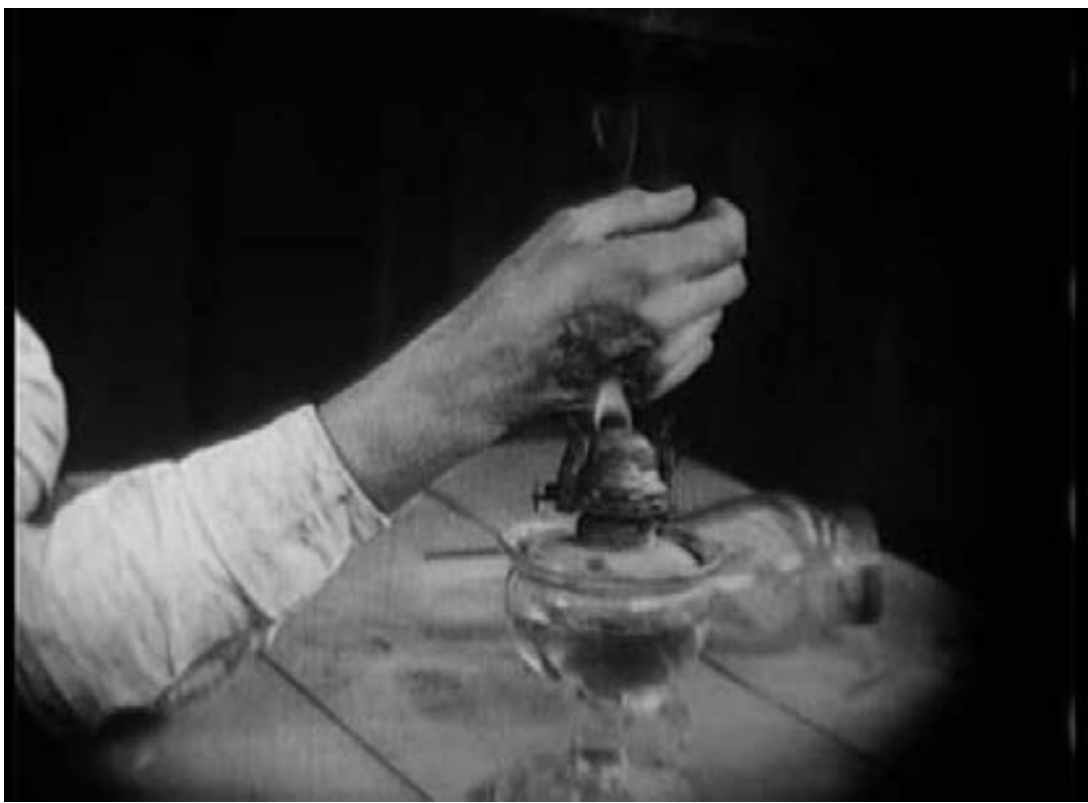

11. Don Mackay (Bruce Gordon) keeps himself awake by placing his hand over an oil lamp in THE Timber Queen (Roland, 1922), episode 4, 'Go Get Your Man'.

lines between actors and characters especially though similar or identical first names - Pearl White as Pearl Dare in PEARL of THE ARMY, Pearl Travers in Plunder, etc.- - the newspaper and magazine discourse insisted on the actual physical danger to which the actresses were exposed during filming. According to Bean, this insistence on the dangers of stunt filming imposes a quality of the real, which in turn introduces a possibility of 'discontinuity, interruption, accident' to the film: 'If the lived sense of the real turns on chaos, happenstance, and chance, then the real is that which refuses the systematic control of machines, the propensity to regulate, standardize, and serialize' (2001:18-32). Serials thus referenced the reality of their heroines' imperilments to counteract their own highly standardized and controlled nature.

The conflation of actress/actor and character at the time worked in two ways: serials either showcased stars who were already famous for their physical skills, such as Harry Houdini or boxers like Jack Dempsey and Benny Leonard, or they equipped their stars with such a background through personal stories and interviews. Media coverage of The Perils of PAuline, for instance, continuously pointed to the supposed similarities between protagonist Pauline Marvin and Pearl White's own qualities of being daring, adventurous, fearless, and self-reliant (Dahlquist 2013b: 11-13). The serial, in fact, adds supposed parallels between actress and character when it 
portrays Pauline's activities as an adventure writer for the Cosmopolitan ${ }^{62}$ but also depicts her eventual aspirations to become an actress. These are not part of the nine-episode edit available today, but the tie-ins reference this plotline, including film stills showing Pauline signing an acting contract with producer and director Louis Gasnier in a cameo appearance. ${ }^{63}$ In such instances, the film and its promotion blur the lines not only between Pearl and Pauline but also between the serials' diegetic world and an extraneous star discourse. Magazine and newspaper accounts, which stressed not only the actress' prowess but also her non-diegetic imperilments, often describe dangerous situations on set and thereby coincidentally explain aspects of film production and on-site shooting. Bean references both instances in which actresses truly engage in the dangerous feats displayed on screen and instances in which the situation during shooting was less dangerous than it appears in the resulting film. In the latter case, Pearl White at times explained how a scene was created (Bean 2001: 26-27). The supposedly shared adventurous character of actress and character and the resulting interest in filming thus feeds back into an aesthetics of the operational, when articles about the actress double as explanations of the processes of stunt filming, whether with actual danger or in clever deceit. ${ }^{64}$ Therefore, the pleasure of watching daredevil stunts and last-minute rescues lies not only in thrill and spectacle but partially also outside of the filmic text, in the engagement with discursive material that enables a glimpse at the processes of filmmaking.

All of these aspects - the showcasing of technical and narrative mechanisms, the display of bodies, the insistence on showing 'real danger', and the concurrent detailing of filmmaking strategies - feed into the presentational quality of film serials, which refuse to locate their attractions solely within the diegetic confines of the filmic world. Far from being restricted to the early years of serials, these tendencies continue into the late years of silent serial production and into the sound era. Prominently, the 1926 serial OFFICER 444 (Goodwill) casts real-life police officers and enacts truly dangerous stunts in order to frame their stories as the portrayal of 'real'

62 At the time, Cosmopolitan was a literary magazine. Pathe was to recruit both the protagonist and the scriptwriter of its following serial, THE Exploits of ELAINE, from the magazine.

63 The Pearl White Clippings at Margret Herrick Library include excerpts from the newspaper novelization with film stills depicting Louis Gasnier and Pearl White as she signs the documents. 64 In fact, Bean describes how magazines published set photographs in order to give viewers a chance to decide for themselves whether a scene was a clever stunt or meant real danger (2001: 25). This decision-making effort echoes the behavior of mid-nineteenth-century visitors to P.T. Barnum's American Museum, who similarly decided for themselves whether the exhibited curiosities were plausible (Harris 1973: 77). 
action rather than scripted stories. The shooting of the serial in Berkeley, California was covered by a local newspaper that highlighted the casting of a traffic officer to appear in the picture, pointing out that the serial would 'advertise Berkeley's police and fire departments all over the world', but also mentioned the injuries suffered by three actors during stunt filming, including another traffic officer (Berkeley Daily Gazette, 1926b; Berkeley Daily Gazette, 1926a). More than ten years after Pearl White's exploits as Pauline, the explanation of an actor's accident during the shooting of OFFICER 444 similarly explained how the stunt itself was effected, detailing some of the technicalities of filmmaking. Such a continued conflation of actors and characters, which transpires here through the casting of police officers to enact police officers in a serial, is taken to an extreme in THE CHINATOWN MysteRY (Trem Carr, 1928), which essentially casts actors as actors in the cameo appearances making up the 'mysterious 13'.

In the sound era, serials continued their presentational efforts and their abjuration of self-containment. In order to point beyond the confinement of the screen, serials used stunts as attractions that conflated actors and on-screen characters through their shared skill-set. Across the decades, film serials established their own circle of star actors and actresses who especially in the sound era were known for their physical prowess. Jo Bonomo, for instance, was famous for his muscle power, and Yakima Canutt's skills as an actor, stuntman, and stunt director account for his remarkably frequent appearance in serials at the time (Tuska 1982: 16-18). ${ }^{65}$ Other examples include child actors who were unusually versed in horse riding and horse stunts, for instance Betsy King Ross and Frankie Darro, who, similar to actors of the silent era, played parts that shared their first names in The Phantom Empire (Mascot, 1935). Pressbooks from the time similarly stressed the similarities of actors and their roles, for instance when suggested advertisements for FLASH GORDON described its lead actor Buster Crabbe as a 'living "Flash Gordon"'. An article from CAPTAIn MidnighT's pressbook describes such conflations with respect to casting practices, arguing that the most important rule during casting is to 'be yourself'. Instead of masquerading actors into particular characters, according to the article, casters were looking for 'types', that is, for people resembling aviators, FBI agents, or army officers in their daily lives. Conversely, the pressbook for The Clutching HAND argues that its fictional Detective Craig Kennedy 'is very much a person; and, even though he has never

65 Cannutt's popularity also becomes evident in the pressbook for THE Clutching Hand, which includes an article headed 'If Cannutt Can Not Do It — Then It Just Can't Be Done'. 
walked in shoe leather save across the written page, he lives and breathes, even as you and I'.

The presentational qualities of film serials during the sound era are manifold, and most of them can also be found in the late silent era. In fact, Nat Levine, whose production company Mascot Pictures released a number of serials and was responsible for the success of Republic serials after the studio bought Mascot in 1935, used marketing and storytelling strategies in the late 1920s that would become stock elements in the sound era (Tuska 1982:10-15). Especially the frequent car chases and accidents that constitute visual spectacles rather than narrative necessities informed both eras. The serials' presentationalism at the time is also apparent in their insistence on staging real police-work or science and in their evocation of specialists extraneous to film production who vouched for adequate depictions. Thus, the pressbook for ACE DRUMmond reports that Amelia Earhart Putnam witnessed the filming of some of the serial's aviation stunts, and FLASH GoRDON's pressbook highlights that scientists marveled at the serials' 'prehistoric monsters', which 'bear close resemblance [...] to the scientific reconstruction of animals that roamed the earth more than ten thousand years ago'. Additionally, a pressbook article for DiCK TRACY RETURNS narrates how five real-life 'G-Men' fired the bullets shown on screen, because the government refused to allow tracer bullets to be sold to film production companies. The same pressbook stresses that the serial's writers studied FBI files and data before writing the script, and the pressbook for the follow-up, Dick TrACY's G-MEN, explains that the adventurous incidences in the serial are 'taken from actual FBI files in Washington'. Such claims to present real stories rather than creating fictional ones continue a silent-era strategy of presenting police work, as it appears for instance in OFFICER 444 (cf. Brasch \& Mayer 2016). It moreover corresponds to the overt presentationalism of sound-era lobby displays, which included 'a real, working dictaphone outfit [...] not a toy, but a finely-made instrument that acts in the same way as the real dictaphones used by F.B.I investigators' according to the pressbook for MANDRAKE THE MAGICIAN, and 'a special display of police laboratory paraphernalia in your lobby' with 'a real rogues' gallery, wanted poster, fingerprint apparatus, guns, tear gas bombs, etc.' as suggested in the pressbook for Holt of the SECRET SERvice. Even the set designs of some serials were marketed as portrayals of real laboratories, as pressbooks for The Clutching HAND and SOS CoAst GuARD suggest. Such references and suggested lobby exhibitions evoked a presentational realism that foregrounds individual showcased narrative, visual, and even tactile attractions. This is just one of the ways in which sound-era serials are markedly presentational. 
Similar to silent-era exemplifications of how film can tell stories, sound serials continued to allow diegetic characters to comment on the narrative. Thus, a character in The PeriLs of NyOKA (Republic, 1942) exclaims 'we have lost much time' at a point when the running episode indeed just stretched an action sequence halfway through the episode to an unusual length in comparison to other serial episodes. More bluntly, another of Nyoka's male companions exclaims 'this is going to be dangerous!' immediately before an attack (Higgins 2016: 119). Whereas such exclamations bluntly foreground the fact of narration, the presentational quality of film serials is not only a consequence of self-directed commentary or of the frequency of stunts. More generally, the increasingly formulaic structure and economic streamlining of film serials in the sound era fostered a presentational quality that encourages the viewers' awareness of narrative schematization, technological mechanisms, and film as a mechanism. It is especially in the interrelations of these three elements that the operational aesthetic of sound serials comes into its own.

Presentational storytelling both enables and fosters an aesthetic of the operational, as the presentation of mechanisms and the monstration of filmic narratives and technologies draws attention to an aesthetics of process. Such attention to process hinges on a reciprocity of repetition and fragmentation: on the one hand, filmic elements become discernible as modular and mobile fragments through their repeated use, and on the other hand, the refusal to smoothen the seams between such fragments foregrounds the modular composition of serials and fosters an awareness of repetition. Higgins illustrates the modularity and the operational aesthetic of sound serials drawing on an example from ThE PHANTOM EMPIRE (Mascot, 1935). In the serial's first episode, the young ranch resident Betsy goes to see her brother Frankie in his secret laboratory in the hayloft of a barn. In order to get there, Betsy spins a wheel that lowers a rope ladder, steps on the ladder and ascends on it by another spin of the wheel. The mechanism simultaneously opens a trap door to the upper level. Betsy then pushes a button on the wall that lights a lightbulb on Frankie's desk in the adjoining room and, with another push of a button, Frankie opens an automatic sliding door and lets her in. In such instances, serials value procedure over plot, that is, they embellish simple plot points using complex mechanisms. In Higgins' terms, they 'throw emphasis behind "how" things happen, rather than "what" happens' (2016: 50). In addition to establishing Frankie's skills in mechanical engineering, the display of process in this scene constitutes a pleasurable viewing experience in itself. Furthermore, it demonstrates the division of a simple task (climbing a ladder) into an array of Goldbergian 
steps and its concurrent, radically inefficient expansion over time (cf. Higgins 2016: 51). Similarly inefficient processes marked many cliffhanger endings at the time. Taking a multi-step death contraption in CAPTAIN AMERICA (Republic, 1944) as an example, Higgins describes such lethal apparatuses as 'astonishingly inefficient malevolence' and points out that such a cliffhanger is 'wildly implausible but physically precise, fascinating in its complicated operation but simple in its function, and unabashedly presentational' (p. 145).

These small-scale instances that foreground both compartmentalization and the combination of component modules into chains of cause and effect can be considered emblematic of the presentational storytelling in film serials more generally. Whole serials similarly take episodes as their component parts, and episodes are again composed of narrative, visual, technological, or generic components that recur, repeat, and appear in processual arrangements. J.P. Telotte places this composite character in relation to the historical context of the 1930s and 1940s, in which the industrial paradigms of serial storytelling as established during the nineteenth century-'repetition, regularity, and predictable results' - began to be experienced in terms of their increasing 'sway over the human' (1995: 96). Discernible parts such as the setting up of the initial conflict in episode one, its reiteration in each episode's initial recap, and so forth are elements of a machine, of a standardized industrial product offering a recurrent and predictable film experience. They are both safe and comfortable. We simply inhabit[ed] its peculiarly conventionalized region for a time, step[ped] in as we might in a roller coaster car, and enjoy[ed] its almost predictable thrills for the known duration of the ride' (p. 97). ${ }^{66}$ These 'machine-age characteristics' of the serial form, according to Telotte, are the reason why serials accommodate 'image stores of the technological', that is, they are the prime site for science fiction before the genre's breakthrough in feature films in the 1950s (1995, p. 96). Telotte's reading thus shows again how the form's narrative formula and its featured component parts, here in the form of generic props, interrelate.

Telotte's observations rest upon Cecilia Tichi's argument that 'the machineage text does not only contain representations of the machine-it too is the machine. It is a functional system of component parts designed to transmit energy' (Tichi 1987:16). Tichi's generalization of the works of canonized

66 However, Telotte goes on to note that serials could only be successful by hiding their repetitive narrative formula and the repetition of footage, in the recaps and elsewhere, because audiences would cease to come to the cinema if they understood the formula (1995: 97). Conversely, I argue that the serials' foregrounding of narrative, form, and repetition speaks against the claim that serials 'tricked' audiences into continuing to view the serial. 
modernist writers, whose 'fiction and poetry became recognizable as designed assemblies of component parts, including prefabricated parts', is an oddly apt description of the structural set-up of film serials, especially during the sound era (p.16). ${ }^{6}$ The components of serial episodes come together on a number of levels, from broad narrative structures and stock characters down to individual takes and frames. Higgins describes the most readily identifiable modules as the five-part formula: the individual episodes of almost all serials of the sound era combine three action sequences - at the beginning, middle, and at the end - with two intermediate narrative expositions, which at times include the descriptions of mechanisms such as the rope-ladder-door contraption in Frankie's laboratory in THE PHANTOM EMPIRE (Higgins 2016: 29-38). Whereas the five-part formula stabilizes the viewers' experience and makes the serialized story easy to follow, the characters, settings, storylines, technologies, and mechanisms repeat across serials to an extent that makes them also easily identifiable as readymade modular elements. Cowboys, greedy capitalists or similarly greedy archaeologists, brave children, heroic policemen or firemen with comic sidekicks, 'plucky' females, skilled animals, and crazy scientists appear again and again, and narratives of abduction and rescue, brain-alteration and memory loss, hypnotism, surveillance and detection, and hunts for secret scientific formulae and mystical objects recur reliably. Car chases, death traps, featured technologies, and science fiction apparatuses are omnipresent, even in the Westerns. Spying devices, radio-controlled cars, airships, robots, and so forth in fact amount to 'a kind of cinematic World's Fair experience', according to Telotte (1995: 99). These devices at times foreground the technologies of film production when they appropriate production equipment as props. In THE AMAZING ExPLOITS OF THE Clutching HAND (1936), for instance, the eponymous master villain employs a spotlight to interrogate unreliable henchmen before executing them. This instance combines the presentational foregrounding of the spotlight with a reference to the famous villain's first appearance on the film screen, where a similar spotlight doubles as a deadly death ray (THE ExPLOITS of ELAINE, episode 9, 'The Death Ray'). Moreover, it exemplifies how, in the playful world of film serials, the technologies of film production are also component parts that are conveniently ready to be appropriated on screen.

More generally, serials utilized previously filmed material and stock footage, recycling both film strips and props. THE VANISHING LEGION, for

67 In an ongoing study, Svenja Fehlhaber questions the absoluteness of Tichi's descriptions and establishes alternate modernisms by reference to authors that have until now been excluded from the American high-modernist canon. 
instance, includes stunt footage of the black horse Rex, which was originally shot for WiLd Honse Mesa (Paramount, 1925) and reused later in the films The Strawberry Roan (Universal, 1933) and Hit the Saddle (Republic, 1937) (Tuska 1982: 17-18). Similarly, FLASH GoRDON uses props from Fran KENSTEIN and The Mummy (1932), and it incorporates newsreel footage, including shots of Charles Lindbergh landing his airplane in Paris. According to Higgins, among the serials that most thoroughly profited from such bricolage is The Great Alaskan Mystery (Universal, 1944), which assembles stunts and location shots from various more expensive features (2016: 127-32). In addition to such extraneous sources of image material, serials also recycled footage from their own production processes, at times outright repeating instances from just a few episodes earlier - especially of rather expensive stunt sequences. Thus, the hero's car crash in the ninth episode of THE VANISHING LEGION (Mascot, 1931) is actually a crash used previously in the same serial. But also less action-oriented scenes are repeated in the serial, for instance when its hero Happy Cardigan (Harry Carey) is captured twice and each time refuses to disclose crucial information, telling his abductors: 'Can't get water out of a dry well, mister!' (episode 7 , 'The Crimson Cue'). ${ }^{68}$ Whereas such repetitions were a radically commercial-industrial means of creating a cheap product, ${ }^{69}$ they also highlight a serial's montage character and the component elements it combines.

At times, serials made attempts to integrate repeat footage more seamlessly. In The Amazing Exploits of the Clutching HAND, for instance, Detective Kennedy watches a recording of an earlier instance in the serial on a televisual surveillance apparatus in his laboratory. In fact, the sequence shown within the diegetic television frame repeats an instance from the same episode (episode 6, 'Steps of Doom'). Similarly, the queen of THE PhANTOM EMPIRE's underground kingdom surveils American society on a television screen that shows stock footage of car races, sporting events, war scenes, etc. (episode 1, 'The Singing Cowboy'; episode 2, 'The Thunder Riders'). Nevertheless, these strategies fail to integrate repeated or stock footage seamlessly, because its integration through diegetic technologies fosters an awareness of fragmentation rather than working towards suture. This failure results from the presentational mode of address itself: serials

68 Whereas it is known that serials at the time used repeat footage, the actual extent of the practice is difficult to assess because some digitally restored release formats also copy and paste sequences from a serial to restore missing scenes.

69 The repetition of the cliffhanger in an episode's beginning is also generally financially lucrative. 
present or exhibit these surveillance mechanisms, turning the repeated or stock footage into examples of a working mechanism, that is, of an 'attraction' in Gunning's use of the term (cf. 1986). Repeated and recycled footage exemplifies a diegetic television's surveillance or recording capacity and it instantiates the exhibition of these mechanisms.

The serials' at times rather overt editing fed into their presentational character. Despite being shared by many contemporaneous features, arrowshaped or v-shaped optical wipes highlighted the transition from one scene to another graphically and thereby underlined the fragmented nature of the filmic image. Again, despite the fact that numerous films without any relation to comic strips employed similar techniques, such optical wipes were nevertheless reminiscent of comics' panels. They showed, at a micro level, how film itself is made up of component frames that are arranged through editing. The optical wipe within a filmic product that is already closely aligned with comic strip culture thus is a reference to what in comic studies is considered the 'gutter': the interstice between panels that leaves room for the imagination (cf. Gardner 2012: 22, 34). More generally, such visual techniques exemplified the possibility of a showcasing of composition and compartmentalization on the film screen, in independent productions as well as in the products of the major film studios. To return to the previous example: when serials frame repeat footage through diegetic technologies, they position the gutter in the picture, between our perception of the image and our perception of diegetic characters' acts of perception. Instead of smoothening the stitch between two fragments, diegetic technologies turn the gutter into a prop.

All of these components, on all of these multiple levels, are parts of the film serial machine. According to Tichi's account of modernist writing, 'the components must all function systematically. There must be no unnecessary parts to lessen efficiency' (1987: 16). Whereas in the context of Taylorist-Fordist production, serialization and efficiency work as well as in the serial output of the film industry, the film serial as a product is, by contrast, pronouncedly inefficient. Instead of presenting a mystery and its step-by-step resolution, film serials add numerous steps in between in order to extend the narrative across ten to fifteen episodes. Especially the repetition of footage within a single serial is ineffective. Viewers do not learn anything new about the story, but the footage takes up time and delays a serial's narrative resolution. Metaphorically speaking, it is as though Ford was adding random extra fenders to his assembly-line cars. Film serials, that is, are purposely inefficient machines.

Thinking of film in terms of components brings us back to the trick cliffhangers discussed above. Such cliffhangers typically show the inescapable 
death of a hero in a car crash or explosion, or after falling from a cliff, bridge, or airplane, and the following week they repeat the incident but add an extra shot before the crash that shows the protagonist's last-second escape. A very blunt example of this occurs in The Amazing Exploits of THE Clutching Hand: Detective Kennedy and his comrade Jameson dovetail a villain's car and follow it into a barn, which has sliding doors on either side. Whereas the villain's car emerges on the barn's other end, Kennedy's car and the people inside are supposedly killed when the barn explodes. The following episode repeats the car chase, but it shows Kennedy's sedan emerging from the barn right before the explosion (episode 4, 'The Phantom Car'; episode 5, 'The Double Trap'). Higgins refers to this filmic technique as 'hidden ellipses', and he considers them 'the most common means of resolving cliffhangers' in the sound era (2016:100). In fact, the strategy was used throughout the 1930 s and 1940 s to such an extent that no serial fan could have missed it, but this also means that this cliffhanging strategy could not have diminished a serial's overall appeal. Instead, the cubic element already present in the silent era intensified in the sound serial's insistence on the gutter. If individual shots are component parts of, rather than instances bound up in, a chronological sequence of events, their retrospective addition is part of a presentational mode and technique of storytelling rather than a 'trick' played on the viewers. As monstration rather than representational storytelling, such inserted shots confirm that a single added component suffices to turn the effective killing of a character into an ineffective story twist that is of no immediate consequence. The viewers' interest in the 'how' of filmic storytelling thus takes place at a micro level as viewers watching a cliffhanger sequence may wonder where the added sequence of images that shows the hero's escape will be inserted the following week. The question of how the protagonist escaped death translates into the question of where the film adds frames, shots, or takes to the scene. Sound serials thus literalize what theorists from Siegfried Kracauer to Roland Barthes and Jean-François Lyotard lamented as suture's loss: 'the interstices between the film's images opened up for perverse engagements' (Gardner 2012: 5).

This presentational foregrounding of the compartmentalized structure of film serials is what differentiates them most profoundly from other filmic forms. The difference becomes especially apparent in a comparison of the work of special effects wizard Kenneth Strickfaden. Strickfaden famously engineered the Tesla coil effects in FrAN KEnSTEIN (Universal, 1931), The Mummy (Universal, 1932), and The Mask of Fu Manchu (MGM, 1932). Afterwards, he was again employed for the production of the film serials The Lost City (Krellberg, 1935), The Amazing Exploits of the 
Clutching Hand (Weiss, 1936), and Flash Gordon (Universal, 1936). In FrANKENSTEIN as well as in THE MASK, Tesla coil effects and electricity as a force more generally are portrayed in a combination of alternating shots of the electrical stunt and its diegetic admirers. This visualization foregrounds electricity as the force behind cinematic animation, and diegetic characters stand in for the film viewers (Denson 2014a: 87; Mayer 2014: 69). With reference to Siegfried Kracauer's 1926 account of the 'electric power plant' that enables film production, Ruth Mayer explains that electric lighting and the masks or make-up of actors together efface the fragmented relation of actors and non-human objects in the screen image (Mayer 2014: 72-73). In film production, electricity effects 'the realignment of the fragmented experience in the modern world' (p. 72). In THE MASK, Strickfaden's effects result in a 'markedly aestheticized enactment of electricity' (p. 69). They are employed in scenes that can be easily singled out from the rest of the films. In fact, the use of Tesla coil effects is similarly limited in time in its earlier incarnation in the silent serial THE PowER GoD (Davis, 1925), where it is used twice across fifteen chapters. The film serials of 1935 and 1936, by contrast, use Strickfaden's effects multiple times per episode. In the initial episode of THE LOsT CITY, electrical sparks are dispersed throughout the set to an extent that makes them part of the background rather than any stylized, foregrounded stunt (episode 1, 'Living Dead-Men'). Instead of unifying fragmented elements of and in the filmic image, the electrical sparks signify a constant flow of electrical impulses that are themselves as fragmentized as the serial form. In a pointed contradiction, the villain in THE Lost CiтY employs electricity in a way that directly opposes its earlier use in FRANKENSTEIN: whereas Whale's film stages Tesla coil effects to picture the electric current animating its monster, the serial's villain destroys living people's brains to create robotic giants referred to as 'living dead-men' (episode 1, 'Living Dead-Men'). Even though the creation of Frankenstein's monster itself draws attention to the Benjaminian reproducibility of film (cf. Denson 2014a: 88), THE Lost CITY takes this to an extreme by visualizing the seriality of the process: 'Living dead-men', we learn, roam the African jungle one behind the other, capturing people and carrying them to the lost city, where one after another will have their brains removed and their physical statures enlarged (episode 1 , 'Living Dead-Men'). ${ }^{70}$ Not only are the robot-men produced serially, they also endlessly self-perpetuate. Instead

70 These scenes, I should add, display a pronounced racism, as the 'living dead-men' are recruited exclusively from black characters living in the African jungles around the lost city, who, having undergone the brain deletion procedure, continuously utter apish groans. 
of including one animation scene, the electrical currents of the film serial perform a serial animation. 'Living dead-men' thus embody the perpetual propelling of serialized production and fragmentary storytelling as it is taken to an extreme. This gesturing towards excess is part of the serials' thriving on presentist and presentational modes of storytelling. Serials foreground and celebrate fragmentation, they admittedly benefit from compartmentalization, and they showcase the manifold ways in which they do so. The result is a radically exteriorized narrative that reaches beyond the confines of the screen both in the form of a marketing that branches out across a small town's business center and in terms of an audience address that never ceases to reference its own artificial character and creation.

\section{Bibliography}

Ace Drummond. Dir. Ford Beebe and Clifford Smith. Perf. Noah Beery Jr., John King, Jean Rogers. Universal, 1936.

Ace Drummond (Universal, 1936). Pressbook. New York Public Library for the Performing Arts, Dorothy and Lewis. B. Cullman Center.

Altman, Rick. 2004. Silent Film Sound. New York: Columbia University Press.

Barefoot, Guy. 2011. "Who Watched That Masked Man? Hollywood's Serial Audiences in the 1930s." Historical Journal of Film, Radio and Television 31 (2):167-90.

Bean, Jennifer M. 2001. "Technologies of Early Stardom and the Extraordinary Body." Camera Obscura 16 (3): 9-58.

The Beloved Adventurer. Dir. Arthur V. Johnson. Perf. Lottie Briscoe, Florence Hackett, Arthur V. Johnson. Lubin, 1914.

Berkeley Daily Gazette. 1926a. “2 Movie Actors Injured Jumping,” January 9.

—.1926b. "Movie Contract Offered Fisher," January 9.

Bordwell, David, and Kristin Thompson. 2008. Film Art: An Introduction. 8th ed. New York: McGraw-Hill.

Boys' Life. 1927. “Advertisement,” January. google books.

Brasch, Ilka, and Ruth Mayer. 2016. "Modernity Management: 1920s Cinema, Mass Culture and the Film Serial." Screen 57 (3).

Burns, William J. 1914a. "Helps to the Solution of The Million Dollar Mystery." The Movie Pictorial, July 4, 1914. archive.org.

—. 1914b. "Helps to the Solution of The Million Dollar Mystery." The Movie Pictorial, July 11. archive.org.

Canjels, Rudmer. 2011. Distributing Silent Film Serials: Local Practices, Changing Forms, Cultural Transformation. Routledge Advances in Film Studies 7. New York: Routledge.

Captain America. Dir. Elmer Clifton, John English. Perf. Lionel Atwill, Dick Purcell, Lorna Gray. Republic, 1944 .

Captain America (Republic, 1944). Pressbook. New York Public Library for the Performing Arts, Dorothy and Lewis. B. Cullman Center.

Captain Midnight. Dir. James W. Horne. Perf. James Craven, Dave O'Brien, Dorothy Short. Columbia, 1942. 
Captain Midnight (Columbia, 1942). Pressbook. New York Public Library for the Performing Arts, Dorothy and Lewis. B. Cullman Center.

Cole, Simon A. 2001. Suspect Identities: A History of Fingerprinting and Criminal Identification. Cambridge, MA: Harvard University Press.

Curtis, Scott. 2004. "A House Divided: The MPPC in Transition." In American Cinema's Transitional Era: Audiences, Institutions, Practices, edited by Charlie Keil and Shelley Stamp, pp. 239-64. Berkeley: University of California Press.

Dahlquist, Marina. 2013a. Exporting Perilous Pauline: Pearl White and the Serial Film Craze. Chicago: University of Illinois Press.

—. 2013b. "Introduction: Why Pearl?" In Exporting Perilous Pauline: Pearl White and the Serial Film Craze, edited by Marina Dahlquist, pp. 1-24. Chicago: University of Illinois Press.

DaredevilJack. Dir. W.S. Van Dyke. Perf. Jack Dempsey, Herschel Mayall, Josie Sedgwick. Pathe/ Astra, 1920.

DaredevilJack (Astra/Pathe, 1920). Pressbook. University of California in Los Angeles, Young Research Library, Special Collections.

Denson, Shane. 2008. "Tarzan Und Der Tonfilm. Verhandlungen Zwischen 'Science' Und 'Fiction.” In "Ich Tarzan." Affenmenschen Und Menschenaffen Zwischen Science Und Fiction, edited by Gesine Krüger, Ruth Mayer, and Marianne Sommer, pp. 113-3o. Bielefeld: transcript.

-. 2014a. Postnaturalism: Frankenstein, Film, and the Anthropotechnical Interface. Bielefeld: transcript.

- 2014b. "The Logic of the Line Segment: Continuity and Discontinuity in the Serial-Queen Melodrama." In Serialization in Popular Culture, edited by Robert Allen and Thijs van den Berg, pp. 65-79. New York: Routledge.

Dick Tracy. Dir. Alan James and Ray Taylor. Perf. Smiley Burnette, Ralph Byrd, Kay Hughes. Republic, 1937.

Dick Tracy Returns. Dir. William Witney, John English. Perf. Ralph Byrd, Charles Middleton, Lynne Roberts. Republic, 1938.

Dick Tracy Returns (Republic, 1938). Pressbook. New York Public Library for the Performing Arts, Dorothy and Lewis. B. Cullman Center.

Dick Tracy's G-Men. Dir. William Witney, John English. Perf. Ralph Byrd, Phyllis Isley, Irving Pichel. Republic, 1939.

Engell, Lorenz. 2011. "Erinnern/Vergessen. Serien Als Operatives Gedächtnis Des Fernsehens.” In Serielle Formen. Von Den Frühen Film-Serials Zu Aktuellen Quality-TV Und Online-Serien, edited by Robert Blanchet, Kristina Köhler, Tereza Smid, and Julia Zutavern, pp. 115-33. Zürcher Filmstudien 25. Marburg: Schüren.

Enstad, Nan. 1995. "Dressed for Adventure: Working Women and Silent Movie Serials in the 1910s." Feminist Studies 21 (1): 67-90.

Exhibitor's Herald. 1920a. "Leonard Company to Make Exteriors While En Route to Western Studio," March 6.

—. 192ob. "Produce First Psychic Serial," March 6.

Exhibitor's Trade Review. 1921. "How to Properly Exploit Newest Jungle Sensation," September 24.

—.1925a. "A Good Serial Is the Biggest Box Office Builder," February 14.

-.1925b. "Serial Pictures - A Powerful Competitive Weapon," February 14.

-. 1925c. "Serial Pictures Will Help to Stabilize Your Attendance - Give Them a Chance," February 14.

-. 1925d. "The Pessimist's Window," February 14.

Flash Gordon. Dir. Frederick Stephani. Perf. Buster Crabbe, Charles M. Middleton, Jean Rogers. Universal, 1936. 
Flash Gordon (Universal, 1936). Pressbook. New York Public Library for the Performing Arts, Dorothy and Lewis. B. Cullman Center.

Frankenstein. Dir. James Whale. Perf. Mae Clarke, Colin Clive, Boris Karloff. Universal, 1931.

Gardner, Jared. 2012. Projections: Comics and the History of Twenty-First-Century Storytelling. Stanford: Stanford University Press.

Giebler, A. H. 1915. "St. Louis Girl Wins Prize." The Moving Picture World, March 13.

Gomery, Douglas. 2005. The Coming of Sound: A History. New York: Routledge.

Gunning, Tom. 1986. “The Cinema of Attraction: Early Film, Its Spectator and the Avant-Garde." Wide Angle 8 (3-4): 63-70.

Haenni, Sabine. 2015. “Gender in the Jungle." Conference: Managing Mass Culture, April 25. Hannover.

Hagedorn, Roger. 1988. "Technology and Economic Exploitation: The Serial as a Form of Narrative Presentation." Wide Angle 10 (4): 4-12.

Harris, Neil. 1973. Humbug: The Art of P.T. Barnum. 1st ed. Boston: Little, Brown, and Co.

Henderson, Stuart. 2014. The Hollywood Sequel: History and Form, 1911-2010. Basingstoke, Hampshire: Palgrave Macmillan.

Higgins, Scott. 2016. Matinee Melodrama: Play and the Art of Formula in the Sound Serial. New Brunswick: Rutgers University Press.

Hit the Saddle. Dir. Mack V. Wright. Perf. Ray Corrigan, Rita Hayworth, J.P. McGowan. Republic, 1937.

Holt of the Secret Service. Dir. James W. Horne. Perf. Evelyn Brent, Jack Holt, Montague Shaw. Columbia, 1941.

Holt of the Secret Service (Columbia, 1941). Pressbook. New York Public Library for the Performing Arts, Dorothy and Lewis. B. Cullman Center.

Horak, Jan-Christopher. 1989. Dream Merchants: Making and Selling Films in Hollywood's Golden Age. Rochester: International Museum of Photography at George Eastman House.

Jenner, Mareike. 2016. American TV Detective Dramas: Serial Investigations. Basingstoke, Hampshire: Palgrave Macmillan.

Jess-Cooke, Carolyn. 2009. Film Sequels: Theory and Practice from Hollywood to Bollywood. Edinburgh: Edinburgh University Press.

Kelleter, Frank. 2012. "Populäre Serialität: Eine Einführung." In Populäre Serialität:Narration Evolution - Distinktion: Zum Seriellen Erzählen Seit Dem 19. Jahrhundert, pp. 11-46. Bielefeld: Transcript.

Kelleter, Frank, Ruth Mayer, and Barbara Krah, eds. 2007. Melodrama! The Mode of Excess from Early America to Hollywood. Heidelberg: Universitätsverlag Winter.

King of the Royal Mounted. Dir. William Witney, John English. Perf. Allan Lane, Robert Strange, Herbert Rawlinson. Republic, 1940.

Kinnard, Roy. 2012. "Where It All Began: The Flash Gordon Serials." In 195os "Rocketman" TV Series and Their Fans: Cadets, Rangers, and Junior Space Men, edited by Cynthia J. Miller and A. Bowdoin Van Riper, pp. 17-32. New York: Palgrave Macmillan.

Krämer, Sybille. 1998. "Form Als Vollzug Oder: Was Gewinnen Wir Mit Niklas Luhmanns Unterscheidung von Medium Und Form?" Journal for History of Law (Rechtshistorisches Journal) 17: 558-73.

Loock, Kathleen. 2014. “'The Past Is Never Really Past:' Serial Storytelling from Psycho to Bates Motel." Literatur in Wissenschaft Und Unterricht 47 (1/2): 81-96.

—. 2016. "Sound Memories: 'Talker Remakes,' Paratexts, and the Cinematic Past." In The Politics of Ephemeral Digital Media:Permanence and Obsolescence in Paratexts, edited by Sara Pesce and Paolo Noto, pp. 123-137. New York: Routledge. 
Los Angeles Times. 1937a, October 3. ProQuest.

- 1937b, October 4. ProQuest.

Lucille Love, Girl of Mystery. Dir. Francis Ford. Perf. Grace Cunard, Fancis Ford. Universal, 1914. Luhmann, Niklas. 1997. Die Gesellschaft Der Gesellschaft. Frankfurt am Main: Suhrkamp.

Maltby, Richard. 2003. Hollywood Cinema. 2nd ed. Oxford: Blackwell Publishing.

- 2013. "The Standard Exhibition Contract and the Unwritten History of the Classical Hollywood Cinema." Film History 25 (1-2): 138-53.

Mandrake the Magician. Dir. Norman Denning, Sam Nelson. Perf. Warren Hull, Al Kikume, Doris Weston. Columbia, 1939.

Mandrake, the Magician (Columbia, 1939). Pressbook. New York Public Library for the Performing Arts, Dorothy and Lewis. B. Cullman Center.

Mayer, Ruth. 2014. Serial Fu Manchu: The Chinese Supervillain and the Spread of Yellow Peril Ideology. Philadelphia: Temple University Press.

—. 2016. “'Never Twice the Same': Fantômas' Early Seriality." Modernism/Modernity 23 (2):341-64.

McLean, Adrienne L. 2003. "New Films in Story Form': Movie Story Magazines and Spectatorship." Cinema Journal 42 (3): 3-26.

Metropolis. Dir. Fritz Lang. Perf. Alfred Abel, Gustav Fröhlich, Brigitte Helm. UFA, 1927.

Miller, Cynthia J. 2009. "Defending the Heartland: Technology and the Future in The Phantom Empire (1935)." In Heroes of Film, Comics and American Culture: Essays of Real and Fictional Defenders of Home, edited by Lisa M. DeTora, pp. 61-76. Jefferson, NC: McFarland.

Milne, Peter. 1914. "Lucille Love: The Girl of Mystery." Motion Picture News, July 25.

Morris, Justin J. 2014. "Extratextuality and the Silent Film Serial." Cineaction 94: 45-50.

Motion Picture News. 1914a. "Advertisement for The Perils of Pauline," April 4. Media History Digial Library.

—. 1914b. "Advertisement for Zudora," October 17. Media History Digial Library.

—. 1915a. "Remarkable Mechanical Devices Used in 'Elaine,"” March 6.

—. 1915b. "St. Louis Girl Wins Thanhouser \$10,00o Prize," March 13. Margaret Herrick Library.

Motography. 1914. "Thrills in New Lubin Series," September 26, 1914. Margaret Herrick Library.

Mott, Frank Luther. 1957. A History of American Magazines, 1885-1905. Cambridge, MA: Harvard University Press.

N. W. Ayer \& Son's American Newspaper Annual and Directory. 1913. Philadelphia: N.W. Ayer \& Son Newspaper Agents. https://catalog.hathitrust.org/Record/oo6109711.

New York Journal and American. 1937a. October 3. Columbia University, Butler Library. Microfilm. - 1937b. October 4. Columbia University, Butler Library. Microfilm.

Officer 444. Dir. Francis Ford. Perf. Al Ferguson, Neva Gerber, Ben Wilson. Ben Wilson/Goodwill, 1926.

Pearl of the Army. Dir. Edward Jose. Perf. W. T. Carleton, Marie Wayne, Pearl White. Astra/ Pathe, 1916.

Pearson, Elmer. 1925. "Why They Come Back - An Expert Talks of Audiences and Chapter Plays." Exhibitor's Trade Review, February 14.

Plunder. Dir. George B. Seitz. Perf. Harry Semels, Pearl White, Warren William. Pathe, 1923.

Radio Patrol. Dir. Ford Beebe and Cliff Smith. Perf. Catherine Hughes, Mickey Rentschler, Grant Withers. Universal, 1937.

Radio Patrol (Universal, 1937). Pressbook. New York Public Library for the Performing Arts, Dorothy and Lewis. B. Cullman Center.

Reel Life. 1915. "Facts and Figures and Such," February 27.

Reeve, Arthur B. 1920. "Arthur B. Reeve Assails Effort To Bar Thrill Films From Mails." Exhibitor's Herald, January 24. 
—. 1923. "Craig Kennedy, Radio Detective. Chapter 1: The Radio Robbery." Boys' Life, October. google books.

Secret Agent X-9. Dir. Lewis D. Collins, Ray Taylor. Perf. Lloyd Bridges, Keye Luke, Jan Wiley. Universal, 1945 .

Secret Agent X-9 (Universal, 1937). Pressbook. New York Public Library for the Performing Arts, Dorothy and Lewis. B. Cullman Center.

SherlockJr. Dir. Buster Keaton. Perf. Buster Keaton, Joe Keaton, Kathryn McGuire. MGM, 1924. Silverman, Kaja. 1983. The Subject of Semiotics. New York and Oxford: Oxford University Press. Singer, Ben. 1993. "Fiction Tie-Ins and Narrative Intelligibility 1911-1918." Film History 5 (4): 489-504. —. 1996. "Serial Melodrama and Narrative 'Gesellschaft." The Velvet Light Trap 37 (1): 72-80.

-. 2001. Melodrama and Modernity: Early Sensational Cinema and Its Contexts. New York: Columbia University Press.

Sklar, Robert. 1994. Movie-Made America: A Cultural History of American Movies. New York: Vintage Books.

Solomon, Matthew. 2010. Disappearing Tricks: Silent Film, Houdini, and the New Magic of the Twentieth Century. Urbana and Chicago: University of Illinois Press.

S.O.S. Coast Guard. Dir. Alan James, William Witney. Perf. Ralph Byrd, Maxine Doyle, Bela Lugosi. Republic, 1937.

Spy Smasher. Dir. William Witney. Perf. Marguerite Chapman, Sam Flint, Kane Richmond. Republic, 1942.

Stamp, Shelley. 2000. Movie-Struck Girls: Women and Motion Picture Culture after the Nickelodeon. Princeton: Princeton University Press.

Strawberry Roan. Dir. Alan James. Perf. Harold Goodwin, Ruth Hall, Ken Maynard. Universal, 1933. Sunrise. Dir. F.W. Murnau. Perf. Janet Gaynor, Margaret Livingston, George O'Brien. Fox, 1927. Tarzan the Fearless. Dir. Robert F. Hill. Perf. E. Alyn Warren, Jacqueline Wells, Buster Crabbe. Sol Lesser/Principal, 1933 .

Tarzan the Mighty. Dir. Jack Nelson, Ray Taylor. Perf. Al Ferguson, Natalie Kingston, Frank Merrill. Universal, 1928.

Tarzan the Tiger. Dir. Henry McRae. Perf. Al Ferguson, Natalie Kingston, Frank Merrill. Universal, 1929.

Telotte, J. P. 1995. Replications: A Robotic History of the Science Fiction Film. Urbana and Chicago: University of Illinois Press.

The Ace of Scotland Yard. Dir. Ray Taylor. Perf. Grace Cunard, Crauford Kent, Monte Montague. Universal, 1929 .

The Adventures of Kathlyn. Dir. Francis J. Grandon. Perf. Charles Clary, Lafe McKee, Kathlyn Williams. Selig, 1913.

The Adventures of Tarzan. Dir. Robert F. Hill, Scott Sidney. Perf. Elmo Lincoln, Louise Lorraine, Scott Pembroke. Great Western/Numa, 1921.

The Amazing Exploits of the Clutching Hand. Dir. Albert Herman. Perf. Rex Lease, Ruth Mix, Jack Mulhall. Weiss, 1936.

The Amazing Exploits of the Clutching Hand (Weiss, 1936). Pressbook. New York Public Library for the Performing Arts, Dorothy and Lewis. B. Cullman Center.

The Black Secret. Dir. George B. Seitz. Perf. Wallace McCutcheon Jr., Walter McGrail, Pearl White. George Seitz/Pathe, 1919.

The Chinatown Mystery. Dir. J. P. McGowan. Perf. Joe Bonomo, Francis Ford, Ruth Hiatt. Syndicate, 1928.

The Evil Eye. Dir. J. Gordon Cooper, Wally Van. Perf. Ruth Dwyer, Stuart Holmes, Benny Leonard. Hallmark/Asher's, 1920. 
The Exploits of Elaine. Dir. Louis J. Gasnier, George B. Seitz, Leopold Wharton, and Theodore Wharton. Perf. Arnold Daly, Creighton Hale, Pearl White. Pathe, 1914-1915.

The Fighting Marine. Dir. Spencer Gordon Bennett. Perf. Marjorie Day, Walter Miller, Gene Tunney. Pathe, 1926.

The Great Alaskan Mystery. Dir. Lewis D. Collins, Ray Taylor. Perf. Edgar Kennedy, Milburn Stone, Marjorie Weaver. Universal, 1944.

The Hazards of Helen. Dir. J.P. McGowan, James Davis. Perf. Helen Gibson, Helen Holmes. Kalem, 1914-1917.

The Hope Diamond Mystery. Dir. Stuart Paton. Perf. George Chesebro, Grace Darmond, Boris Karloff. Kosmik, 1920.

The Indians are Coming. Dir. Henry MacRae. Perf. Edmund Cobb, Tim McCoy, Allene Ray. Universal, 1930.

The Jazz Singer. Dir. Alan Crosland. Perf. Eugenie Besserer, Al Jolson, Warner Oland. Warner Bros., 1927.

The King of the Kongo. Dir. Richard Thorpe. Perf. Boris Karloff, Jacqueline Logan, Walter Miller. Mascot, 1929.

The Lone Ranger. Dir. William Witney, John English. Perf. Lee Powell, Hal Taliaferro, Chief Thundercloud. Republic, 1938.

The Lost City. Dir. Harry Revier. Perf. William 'Stage' Boyd, Claudia Dell, Kane Richmond. Krellberg, 1935 .

The Mask of Fu Manchu. Dir. Charles Brabin. Perf. Boris Karloff, Myrna Loy, Lewis Stone. Cosmopolitan/MGM, 1932.

The Master Mystery. Dir. Burton L. King. Perf. Jack Burns, Harry Houdini, Marguerite Marsh. B.A. Rolfe, 1919.

The Million Dollar Mystery. Dir. Howell Hansel. Perf. Florence La Badie, James Cruze, Marguerite Snow. Thanhouser, 1914.

The Moving Picture World. 1914. "New Pathe-Hearst Serial," December 12. Media History Digital Library.

The Mummy. Dir. Karl Freund. Perf. Zita Johann, Boris Karloff, David Manners. Universal, 1932. The Mystery Mind. Dir. Will S. Davis, Fred Sittenham. Perf. Violet MacMillan, Paul Panzer, J. Robert Pauline. Supreme, 1920.

The New Adventures of Tarzan. Dir. Edward Kull, Wilbur F. McGaugh. Perf. Herman Brix, Ashton Dearholt, Ula Holt. E. R. Burroughts, Ashton Dearholt/Burroughs-Tarzan, 1935.

The Perils of Pauline (Universal, 1933). Pressbook. New York Public Library for the Performing Arts, Dorothy and Lewis. B. Cullman Center.

The Perils of Nyoka. Dir. William Witney. Perf. Kay Aldridge, Lorna Gray, Clayton Moore. Republic, 1942.

The Phantom Empire. Dir. Otto Brower and Breezy Eason. Perf. Gene Autry, Frankie Darro, Betsy King Ross. Mascot, 1935 .

The Power God. Dir. Francis Ford. Perf. Al Ernest Garcia, Neva Gerber, Ben Wilson. Ben Wilson/ Goodwill, 1925 .

The Radio Detective. Dir. William James Craft, William A. Crinley. Perf. Jack Dogherty, Jack Mower, Margaret Quimby. Universal, 1926.

The Republic Yearbook. 1937-38. Pressbook. New York Public Library for the Performing Arts, Dorothy and Lewis. B. Cullman Center.

The Son of Tarzan. Dir. Arthur J. Flaven, Harry Revier. Perf. Manilla Martan, Kamuela C. Searle, P. Dempsey Tabler. National, 1920. 
The Vanishing Legion. Dir. Ford Beebe and B. Reeves Eason. Perf. Edwina Booth, Harry Carey, Frankie Darro. Mascot, 1931.

The Voice from the Sky. Dir. Ben F. Wilson. Perf. Neva Gerber, Wally Wales, Robert Walker. Hollywood, 1930.

Tichi, Cecelia. 1987. Shifting Gears: Technology, Literature, Culture in Modernist America. Chapel Hill: University of North Carolina Press.

The Timber Queen. Dir. Fred Jackman. Perf. Bruce Gordon, Val Paul, Ruth Roland. Ruth Roland Serials/Pathe, 1922.

Tim Tyler's Luck. Dir. Ford Beebe, Wyndham Gittens. Perf. Jack Mulhall, Frances Robinson, Frankie Thomas. Universal, 1937.

Tim Tyler's Luck (Universal, 1937). Pressbook. New York Public Library for the Performing Arts, Dorothy and Lewis. B. Cullman Center.

Todorov, Tzvetan. 1977. "The Typology of Detective Fiction." In The Poetics of Prose, pp. 42-52. Oxford: Blackwell.

Tuska, Jon. 1982. The Vanishing Legion: A History of Mascot Pictures 1927-1935. Jefferson, NC: McFarland.

Tzioumakis, Yannis. 2006. American Independent Cinema: An Introduction. Edinburgh: Edinburgh University Press.

Usai, Paolo Cherchi. 2015. "Introduction for a Screening of The Chinatown Mystery." Conference: Serialities 1915/2015. University of California at Berkeley.

Vela, Rafael. 2000. "With the Parents' Consent: Film Serials, Consumerism and the Creation of the Youth Audience, 1913-1938." Madison: University of Wisconsin-Madison (PhD dissertation).

Washington Times. 1914. "Washington Man Has New Idea For a Serial Film Story," September 17. Emmett C. Hall Scrapbooks. Margaret Herrick Library.

What Happened to Mary. Dir. Charles Brabin and Ashley Miller. Perf. Mary Fuller, Marc McDermott, Charles Ogle. Edison, 1912.

Who is Number One? Dir. William Bertram. Perf. Kathleen Clifford, Cullen Landis, Gordon Sackville. Paramount, 1917.

Wild Horse Mesa. Dir. George B. Seitz. Perf. Noah Beery, Sr., Billie Dove, Jack Holt. Famous Players-Lasky/Paramount, 1925.

"William J. Burns." n.d. The FBI: Federal Bureau of Investigation. Accessed 15 July 2018. https:// www.fbi.gov/history/directors/william-j-burns.

Williams, Linda. 1981. Figures of Desire: A Theory and Analysis of Surrealist Film. Berkeley and Los Angeles: University of California Press.

—.1998. "Melodrama Revised." In Refiguring American Film Genres: History and Theory, edited by Nick Browne, pp. 42-88. Berkeley and Los Angeles: University of California Press.

A Woman in Grey. Dir. James Vincent. Perf. Fred C. Jones, Arline Pretty, Henry G. Sell. Serico, 1920.

Zudora (renamed The Twenty Million Dollar Mystery). Dir. Frederick Sullivan. Perf. Harry Benham, James Cruze, Marguerite Snow. Thanhouser, 1914. 